\title{
A QUANTITATIVE ULTRASTRUCTURAL STUDY OF OOCYTES DURING THE EARLY STAGES OF OVARIAN FOLLICULAR DEVELOPMENT IN BOOROOLA AND WILD-TYPE SHEEP
}

\author{
Karen Lee Reader
}

A thesis submitted to the Victoria University of Wellington in fulfilment of the requirements for the degree of Master of Science in Cell and Molecular Bioscience

Victoria University of Wellington 


\section{Abstract}

In the sheep ovary, primordial follicles are formed as an oocyte surrounded by either a single layer of flattened granulosa cells (type 1) or a mixture of flattened and cuboidal granulosa cells (type 1a). Booroola sheep have a mutation in the growth factor receptor, activin-like kinase receptor 6 (ALK6) which is expressed in oocytes of follicles at the type 1 stage of development. In Booroola ewes homozygous for the ALK6 mutation (BB), oocytes undergo precocious maturation that appears to be initiated during the preantral growth phase. The aim of this study was to quantify the ultrastructural features of oocytes of ovarian follicles at the types 1/1a, 2 and 3 stages of development, from BB and wild-type (++) ewes. Ovaries from $6++$ and 5 BB 4 week old ewe lambs were processed for both light microscopy (LM) and electron microscopy (EM). LM and stereological methods were used to estimate the mean volume of the oocytes of each follicular type and genotype. EM images and point counting or linear intercept counting were used to estimate the volume of smooth endoplasmic reticulum (SER), Golgi, mitochondria, vesicles, lipid, ribosomes, zona pellucida (ZP) and cortical granules (CG), and the surface area of the outer and inner mictochondrial membranes, microvilli and cell junctions. Oocytes of type 1/1a follicles of BB animals had a greater diameter than that in ++ animals (BB: $29.76 \pm 0.58 \mu \mathrm{m}$ vs ++: 27.05 $\pm 0.30 \mu \mathrm{m} ; P<0.01)$ but there were no significant genotype differences in the oocyte diameters of type 2 or 3 follicles. As the follicles of ++ animals developed from the type 1 through to the type 3 stage, the volume and 
surface areas of all sub-cellular structures measured within oocytes increased $(P<0.05)$. In oocytes of type $1 / 1$ a follicles of BB animals, the SER, mitochondria and ZP volumes were greater than in ++ animals $(P<0.05)$ as were the surface areas of the outer mitochondrial membranes, oocyte membrane, and zonula adherens type junctions $(P<0.05)$. At the type 2 stage of development the lipid volume was greater in oocytes of ++ animals, and at the type 3 stage of development the ribosomal volume was greater in oocytes of BB animals. These results suggest that the ALK6 mutation in BB animals has influenced the ultrastructural properties of oocytes in the type 1/1a follicle. This early genotype difference in follicular characteristics may influence the rate of follicular development during the early developmental stages. 


\section{Acknowledgements}

This project has been supported financially by a New Economy Research Fund grant from the Foundation for Research Science \& Technology. I would like to thank the following people who have made it possible for me to complete this study:

My manager and supervisor Dr Ken McNatty, who didn't say no when I asked to do a MSc and supported me throughout the process despite the major changes that have occurred in our work and lives during this time.

My manager, Dr Jenny Juengel, for making it possible for me to complete this project.

Dr Bill Jordan for his co-supervision.

My good friend and personal psychologist, Anne O'Connell, for inspiring me to undertake this project, assisting with the ovary perfusions and providing emotional and practical support and advice throughout.

Peter Smith, for patiently teaching me the ovary perfusion, stereology and statistical techniques.

Dr Peter Hurst for advice on the stereological methodology.

Dr St John Wakefield, Allan Mitchell and Richard Easingwood for providing access to their transmission electron microscopes and for providing useful information and advice on electron microscopy.

My good friend and office-mate, Laurel Quirke, for patiently listening to my grumbling and always offering her support.

The Reproduction Group at Wallaceville and Invermay for providing the animals and covering the other work I would normally have been doing, which allowed me to complete this study. 
Dr Joy McIntosh, for mentoring and proof-reading.

My husband and best friend, Michael Wakelin, who supported me in my unending quest for further training.

My son, Guthrie, for stretching me to my limits in every possible way and helping me prove I can be a mum and play a role in scientific research, all with very little sleep.

This work is dedicated in memory of the Wallaceville Animal Research Centre. 


\section{Contents}

$\begin{array}{lr}\text { Abstract } & 2\end{array}$

$\begin{array}{ll}\text { Acknowledgements } & 4\end{array}$

$\begin{array}{ll}\text { Contents } & 6\end{array}$

$\begin{array}{lr}\text { List of Tables } & 9\end{array}$

$\begin{array}{ll}\text { List of Figures } & 10\end{array}$

$\begin{array}{ll}\text { Abbreviations } & 11\end{array}$

$\begin{array}{lr}\text { 1. Introduction } & 12\end{array}$

1.1 Ovarian follicular morphology and formation 12

1.1.1 Follicular classification 12

$\begin{array}{ll}\text { 1.1.2 Follicular formation } & 13\end{array}$

$\begin{array}{lll}1.2 & \text { Oocyte } & 15\end{array}$

$\begin{array}{lll}1.3 & \text { Ultrastructure of small follicles } & 15\end{array}$

$\begin{array}{ll}\text { 1.3.1 Sheep } & 16\end{array}$

$\begin{array}{ll}\text { 1.3.2 Cow } & 17\end{array}$

$\begin{array}{ll}\text { 1.3.3 Human } & 19\end{array}$

$\begin{array}{lll}\text { 1.3.4 Rhesus Monkey } & 21\end{array}$

$\begin{array}{ll}\text { 1.3.5 Mouse } & 21\end{array}$

1.3.6 Comparison of human and mouse oocyte
ultrastructure

1.4 Initiation and control of follicular growth 24

1.4.1 Transforming growth factor- $\beta$ superfamily 24

1.4.2 Ultrastructure of GDF9 deficient mice 28

1.4.3 ALK6 (BMPRIB) mutation 29

$\begin{array}{lll}1.5 & \text { Aims of this study } & 30\end{array}$ 
2. Materials and Methods

$\begin{array}{lll}2.1 & \text { Animals } & 33\end{array}$

$2.2 \quad$ Fixation \& processing $\quad 34$

$\begin{array}{lll}2.3 & \text { Sectioning } & 38\end{array}$

$\begin{array}{lll}2.4 & \text { Light microscopy } & 39\end{array}$

2.5 Transmission electron microscopy 40

2.6 Estimation of cell component volumes and surface areas 42

$\begin{array}{lll}2.7 & \text { Data analyses } & 43\end{array}$

3. Results 45

3.1 Lamb and ovarian weights 45

$\begin{array}{lll}3.2 & \text { Follicular types } & 47\end{array}$

3.3 Oocyte diameter 48

$\begin{array}{lll}3.4 & \text { General ultrastructure } & 50\end{array}$

3.5 Volume fractions and surface densities of oocyte $\begin{array}{ll}\text { structures } & 57\end{array}$

3.5.1 Changes with follicular type $\quad 57$

3.5.2 Differences between genotypes 57

3.6 Volumes and surface areas 58

3.6.1 Changes with follicular type 58

3.6.2 Differences between genotypes 58

3.7 Zona pellucida and cortical granules 59 
4. Discussion

4.1 Lamb and ovarian weights 65

$\begin{array}{lll}4.2 & \text { Follicular types } & 67\end{array}$

$\begin{array}{lll}4.3 & \text { Oocyte diameter } & 68\end{array}$

4.4 Ultrastructural changes with respect to follicular type $\begin{array}{ll}\text { and genotype } & 70\end{array}$

4.4.1 Comparison with other studies $\quad 70$

$\begin{array}{ll}4.4 .2 \text { Nucleus } & 71\end{array}$

4.4.3 Smooth endoplasmic reticulum 71

$\begin{array}{ll}\text { 4.4.4 Golgi } & 72\end{array}$

$\begin{array}{ll}\text { 4.4.5 Mitochondria } & 72\end{array}$

4.4.6 Mitochondria and SER association 74

$\begin{array}{lll}\text { 4.4.7 Vesicles } & 74\end{array}$

$\begin{array}{ll}4.4 .8 \text { Lipid } & 75\end{array}$

$\begin{array}{lll}4.4 .9 & \text { Ribosomes } & 76\end{array}$

$\begin{array}{ll}\text { 4.4.10 Zona pellucida } & 77\end{array}$

$\begin{array}{ll}\text { 4.4.11 Cortical granules } & 78\end{array}$

$\begin{array}{ll}\text { 4.4.12 Junctions } & 79\end{array}$

$\begin{array}{ll}\text { 4.4.13 Microvilli } & 80\end{array}$

4.5 ALK6 mutation and oocyte ultrastructure 80

$\begin{array}{lll}4.6 & \text { Summary } & 82\end{array}$

$\begin{array}{lll}\text { 5. } & \text { References } & 84\end{array}$

$\begin{array}{lll}\text { 6. } & \text { Appendices } & 88\end{array}$ 


\section{List of Tables}

Table

1. Classification and characterisation of small ovine follicles

2. Summary of ultrastructural changes during the early stages of follicular growth with respect to four species

3. Post-fixation tissue processing method

4. Lamb information and ovarian weights with respect to genotype

5. Percentage of each follicular type with respect to genotype

6. Mean oocyte diameter with respect to follicular type and genotype

7. Mean oocyte diameter of type 1 and 1a follicular types with respect to genotype

8. Mean volume fraction $\left(V_{v}\right)$ of oocyte structures for each follicular type and genotype

9. Mean surface density $\left(S_{v}\right)$ of oocyte structures for each follicular type and genotype

10. Mean volume $\left(\mu \mathrm{m}^{3}\right)$ of oocyte structures for each follicular type and genotype

11. Mean surface area $\left(\mu m^{2}\right)$ of oocyte membranes for each follicular type and genotype

12. Percentage of follicles with ZP and cortical granules present with respect to follicular type and genotype 


\section{List of Figures}

Figure Page

1. BMP/Smad signalling pathway 26

2. Perfusion apparatus 36

3. TEM sampling method $\quad 41$

4. LM images of follicular types 47

5. Correlation between ovarian weight and oocyte diameter of type 1 and 2 follicles $\quad 50$

6. TEM images of type 1 and type 2 follicles 52

7. TEM images of type 3 follicle and oocyte nucleus 53

8. TEM images of organelles in type 2 follicles 54

9. TEM images of lipid droplet and oocyte from type 3 follicle containing Golgi complex and cortical granule 55

10. TEM images of zonula adherens junctions 56 


\section{Abbreviations}

$++\quad$ Non-carrier (wild-type) Booroola ewes

ALK Activin-like kinase

$\mathrm{B}+\quad$ Booroola ewes heterozygous for FecB mutation

BB Booroola ewes homozygous for FecB mutation

BMP Bone morphogenetic protein

CG Cortical granule

EM Electron microscopy

GDF Growth and differentiation factor

GV Germinal vesicle

$\mathrm{LH} \quad$ Luteinising hormone

LM Light microscopy

NaCac Sodium cacodylate

RER Rough endoplasmic reticulum

SER Smooth endoplasmic reticulum

$\mathrm{S}_{\mathrm{v}} \quad$ Surface density

TGF- $\beta \quad$ Transforming growth factor-beta

TEM Transmission electron microscopy

TZP Trans-zonal process

$\mathrm{V}_{\mathrm{v}} \quad$ Volume fraction

ZP Zona pellucida 


\section{Introduction}

A better understanding of ovarian follicular formation and development is likely to provide new insights into regulating fertility. New contraceptive agents could be developed to manage fertility in humans, domestic animals and pest species. The development of new methods for increasing fertility would be beneficial for humans, domestic pets, endangered and agricultural species.

\subsection{Ovarian Follicular Morphology and Formation}

\subsubsection{Follicular classification}

An ovarian follicle consists of a germ cell (the oocyte) surrounded by somatic cells called granulosa cells. During follicular growth the oocyte increases in size, and the number of granulosa cells surrounding the oocyte also increases. Eventually an antral cavity, within the growing follicle, is formed containing follicular fluid. Thereafter, to ovulation, the oocyte diameter increases only slightly. The granulosa cells around the oocyte differentiate into a cumulus phenotype and together with the mural granulosa cells, continue to increase in number. The fluid-filled antrum also continues to expand. A classification system describing the different stages of ovarian follicular development in sheep has been published by Lundy et al., 1999 [1] (Table 1). At the first stage, the follicle is considered to be a primordial (type 1) structure consisting of an oocyte with a single layer of flattened (squamous) granulosa cells. Subsequently, follicles with one layer of a 
mixture of flattened and cuboidal granulosa cells are classified as transitory (type 1a) follicles. Type 2 (primary) follicles consist of one to less than two complete layers of cuboidal granulosa cells. Cuboidal granulosa cells present at the early primary, and all growing follicles from the rat and cow have been shown to stain positively for proliferating cell nuclear antigen indicating they may be undergoing proliferation or DNA repair [2]. Thereafter, the small preantral follicles (type 3) are considered to have from two to fewer than four complete layers of granulosa cells. Large preantral follicles (type 4) have four to less than six complete layers, and small antral follicles (type 5) more than five layers of cuboidal granulosa cells and a fully formed antrum. The zona pellucida (ZP) around the oocyte and theca interna immediately outside the basement membrane of the follicle, begin to form during the type 2 stage of follicular growth in sheep (Table 1).

\subsubsection{Follicular formation}

Primordial follicles in sheep are formed during foetal life in the developing ovary when female germ cells make physical contact with somatic (i.e. pregranulosa) cells. The pre-granulosa cells originate mainly from the ovarian surface epithelium [3]. Follicular formation occurs entirely within ovigerous cords with the emergence of the primordial follicle occurring at the interface of the cortex and medulla. The granulosa cells associated with the oocyte are present either as a single layer of squamous cells (type 1 follicle) or as a mixture of squamous and cuboidal cells (type 1a follicle). Follicular formation appears to be essentially complete by day 100 of foetal development in 
sheep with types 1, 1a and 2 follicles present at this time. No new follicles appear to be formed after birth .

TABLE 1. Classification and characterisation of small ovine follicles (modified from Lundy et al., 1999 [1])

\begin{tabular}{|c|c|c|c|c|c|}
\hline $\begin{array}{c}\text { Follicle } \\
\text { (type) }\end{array}$ & $\begin{array}{c}\text { Total } \\
\text { granulosa } \\
\text { cells } \\
\text { per follicle }\end{array}$ & $\begin{array}{c}\text { Oocyte } \\
\text { diameter } \\
(\mu \mathrm{m})\end{array}$ & $\begin{array}{c}\text { Follicular } \\
\text { diameter } \\
(\mu \mathrm{m})\end{array}$ & $\begin{array}{c}\text { Zona } \\
\text { pellucida } \\
(\%)\end{array}$ & $\begin{array}{c}\text { Theca } \\
\text { interna } \\
(\%)\end{array}$ \\
\hline $\begin{array}{c}\text { Primordial } \\
\text { (type 1) }\end{array}$ & $\begin{array}{c}16 \\
(3,52)\end{array}$ & $\begin{array}{c}34.6 \\
(22.8,52.3)\end{array}$ & $\begin{array}{c}40.8 \\
(28.1,60.5)\end{array}$ & 0 & 0 \\
\hline $\begin{array}{c}\text { Transitory } \\
\text { (type 1a) }\end{array}$ & $\begin{array}{c}39 \\
(9,136)\end{array}$ & $\begin{array}{c}40.6 \\
(27.3,53.0)\end{array}$ & $\begin{array}{c}50.8 \\
(37.3,64.0)\end{array}$ & 0 & 0 \\
\hline $\begin{array}{c}\text { Primary } \\
\text { (type 2) }\end{array}$ & $\begin{array}{c}128 \\
(30,520)\end{array}$ & $\begin{array}{c}52.1 \\
(31.0,80.0)\end{array}$ & $\begin{array}{c}75.2 \\
(49.7,118.8)\end{array}$ & 2 & 35 \\
\hline $\begin{array}{c}\text { Small } \\
\text { preantral } \\
\text { (type 3) }\end{array}$ & $\begin{array}{c}637 \\
(127,2174)\end{array}$ & $\begin{array}{c}72.9 \\
(40.6,92.0)\end{array}$ & $\begin{array}{c}128.5 \\
(63,5,191.0)\end{array}$ & 46 & 100 \\
\hline $\begin{array}{c}\text { Large } \\
\text { preantral } \\
\text { (type 4) }\end{array}$ & $\begin{array}{c}2104 \\
(1090,3404)\end{array}$ & $\begin{array}{c}87.8 \\
(164.2,256.3)\end{array}$ & $\begin{array}{c}194.1 \\
(164.2,256.3)\end{array}$ & 100 & 100 \\
\hline $\begin{array}{c}\text { Small antral } \\
\text { (type 5) }\end{array}$ & $\begin{array}{c}11649 \\
(3425,51447)\end{array}$ & $\begin{array}{c}118.8 \\
(90.9,141.6)\end{array}$ & $\begin{array}{c}326.9 \\
(191.5,450.0)\end{array}$ & 100 & 100 \\
\hline
\end{tabular}

Values for granulosa cells, oocyte diameter and follicular diameter represent geometric means and ranges (in parentheses). 


\subsection{Oocyte}

The oocyte carries the maternal chromosomes for procreation and also supplies the cytoplasm and organelles for embryo development. Oocyte maturation involves both nuclear and cytoplasmic events which are regulated by hormones and mediated by the follicular cells surrounding the oocyte [4]. Immature oocytes in the mammalian ovary have a germinal vesicle (GV). Oocytes are arrested at meiotic prophase until the follicle is stimulated by gonadotrophins during the pre-ovulatory phase to resume maturation: at this time oocytes proceed through metaphase I to metaphase II when a second meiotic arrest occurs. The GV has a well defined nuclear envelope with numerous pores.

\section{$1.3 \quad$ Ultrastructure of small follicles}

Electron microscopy studies have been performed on oocytes and ovarian follicles of many mammalian species, including human, rhesus monkey, mouse, rat, cow, sheep, pig and possum [5-14]. Very few of these studies included quantitative analyses of the ultrastructural differences between the different stages of follicular development and most were descriptive only. 


\subsubsection{Sheep}

In an ultrastructural study by Tassell \& Kennedy, 1980 [12], the oocytes of primordial (type 1) follicles were found to contain round nuclei with several reticulated nucleoli, numerous large pleiomorphic mitochondria and welldeveloped Golgi complexes. Smooth endoplasmic reticulum (SER) was plentiful and often associated with mitochondria. There were a small number of lipid droplets and a highly variable number of electron translucent vesicles, which sometimes contained membrane fragments or crystals. Straight microtubules were also present.

As follicles began to grow, the granulosa cells all became cuboidal and multilayered (type 1a and greater) with ZP material accumulating around the oocyte. Microvilli developed from the oolemma and filaments appeared in the peripheral ooplasm and extended into the microvilli. Some follicles were observed in which the granulosa cells had multiplied but with no evidence of ZP development, or where the ZP had developed but with little change in the granulosa cell numbers. This suggests that these two processes are not necessarily coordinated. During growth of the oocyte, the number of Golgi complexes increased and became peripherally located. In the more advanced follicles, cortical granules appeared close to the Golgi complexes.

Some oocytes in primordial and growing follicles were reported to be undergoing atresia with an increased number of empty vesicles present. In advanced atresia, large irregular vesicles and dense droplets occupied most 
of the oocyte cytoplasm. Changes in the oocyte appeared to precede changes in the granulosa cells.

Matos et al., 2004 [15] described the mitochondria in ovine primordial follicles as having irregular cristae and including elongated forms with parallel cristae. Both SER and rough endoplasmic reticulum (RER) were present, either isolated or in complex associations with mitochondria and vesicles. Sometimes microvilli were present and occasionally ZP material was visible. Unfortunately, Matos did not define what the primordial follicle was in this study and these descriptions may have applied to follicles considered to be types $1,1 \mathrm{a}$ or 2 follicles in the present study.

\subsubsection{Cow}

An ultrastructural study by Fair et al.,1997 [11] examined bovine oocytes from the primordial to early antral stages of follicular growth. The primordial follicles (type 1) had 5 to 8 flattened granulosa cells in the equatorial section through the oocyte nucleus which was located in either a central or eccentric position. Zonula adherens-like junctions were observed between the oocyte and granulosa cells, and in adjacent granulosa cells both gap and zonula adherens-like junctions were present. The oolemma formed coated pits, and coated vesicles were observed in the outer ooplasm indicating that granulosa-oocyte communication may occur through receptor-mediated endocytosis in these follicles. Projections from the oolemma penetrated between adjacent granulosa cells, and a few short bent microvilli were also present. Cytoplasmic organelles were concentrated in the perinuclear region. 
The majority of the mitochondria were round with peripheral longitudinal cristae, although some elongated mictochondria with transverse cristae were present in half of the oocytes. Many of the mitochondria contained large electron-dense granules. Lipid droplets, SER and RER were present in all oocytes. All oocytes, except for one, contained a few Golgi complexes. Polyribosomes were observed on the surface of the RER and throughout the oocyte cytoplasm.

The type 1a follicles were described as activated primordial follicles, and were characterised by a mixture of 5-14 cuboidal and flattened granulosa cells arranged in a single layer around the ooctye at the equatorial section. In most of these follicles, the oocyte nucleus was eccentrically located. There appeared to be a slight increase in the number of microvilli and the frequency of elongated mitochondria. Otherwise these follicles appeared to be ultrastructurally similar to the type 1 follicles.

The primary (type 2) follicles had a single layer of 8-20 cuboidal granulosa cells in the equatorial section. Small patches of ZP material were observed in a few of the follicles. The mitochondria, and in some cases the Golgi complexes, had migrated to the deep cortical region of the oocyte. The number of polyribosomes appeared to have increased and annulate lamellae were observed in one oocyte.

Gap junctions between the oocyte and granulosa cells appeared in the secondary follicles which were described as having a partial or complete 
bilayer of cuboidal granulosa cells. The frequency of coated pits at the oocyte surface was reduced indicating a possible change in the method of granulosa-oocyte communication. ZP material, observed in half of the secondary follicles, was associated with more erect oocyte microvilli and granulosa cell processes extending to the oolemma. Elongated mitochondria became more common and in some oocytes were the predominant form. The number of small cytoplasmic vesicles increased, annulate lamellae were observed occasionally, and a few oocytes contained cortical granules.

In $41 \%$ of type 1 follicles from early postnatal calves, the oocyte nuclei were characteristic of the diplotene stage of meiotic prophase, whereby the nuclear chromatin was aggregated into small, moderately electron-dense patches and the nucleolus had a fibrillo-granular texture [16]. The rest of the type 1 follicles, and the type $1 \mathrm{a}$ and 2 follicles, contained dictyate oocytes in which the chromatin was highly decondensed and the nucleoli were reticulated and differentiated into fibrilla, fibrillo-granular and granular components.

\subsubsection{Human}

In human primordial follicles the oocyte nucleus contained a large reticulated nucleolus [5]. Most of the organelles were concentrated into an area close to the oocyte nucleus, a characteristic known as Balbiani's vitelline body, and annulate lamellae were observed either near or within this structure. The cytocentrum consisted of deposits of amorphous, electron-opaque material, aggregates of closely packed vesicles and coarse, long fibres and was 
surrounded by sparsely granular endoplasmic reticulum (ER). More granular ER was located in the peripheral cytoplasm. Many small Golgi complexes were present at the periphery of the cytocentrum. A mass of mitochondria were found in the Balbiani's vitelline body periphery with some also scattered around the nucleus and peripheral cytoplasm. These were spherical to oval in shape and closely associated with ER. Numerous single or clustered ribosomes were located in the cytoplasm. Vacuoles were observed in the peripheral cytoplasm, and contained either, multiple small vesicles, dense material, electron-opaque granular material or less electron-opaque small vacuoles. Microtubules were observed throughout the oocyte cytoplasm but were more prevalent around the nucleus circumference.

A morphometric ultrastructural study of primordial (type 1), intermediary (type 1a) and primary (type 2) follicles in adult human ovaries was undertaken by de Bruin et al., 2002 [6]. No differences in the areas of the oocytes and oocyte nuclei or nucleus:oocyte ratio were observed for the different follicular stages. The areas of granulosa cells and granulosa cell nuclei increased significantly from the primordial to primary stage, but the nucleus:granulosa cell ratio remained constant at 0.42 . Golgi complexes were not always present and accounted for only a small proportion of the cytoplasmic volume. All follicles contained numerous mitochondria which were either round or elongated with parallel or transverse cristae and had a matrix of moderate density. The profile areas of individual mitochondria showed large variation from 0.05 to $2.33 \mu \mathrm{m}^{2}$. There were no differences observed in the cytoplasmic fractions of lipid droplets, multivesicular bodies, vacuoles, Golgi, 
mitochondria and the mean profile area of mitochondria for the different follicle stages. The organelles were clustered in a Balbiani's vitelline body. The number of zonula adherens junctions between the oocyte and granulosa cells increased from 1.5 in primordial follicles to 3.7 in primary follicles. SER was abundant in all oocytes in vesicular and tubular form closely associated with mitochondria. The numbers of microvilli increased with the stage of follicular development, and the partial presence of ZP increased from $7 \%$ to $19 \%$ from primordial to primary follicles.

\subsubsection{Rhesus monkey}

Oocytes from rhesis monkey primordial follicles exhibited a similar morphology to the human oocytes with the organelles frequently located in a Balbiani's vitelline body [7]. The ER was sparse, agranular, and closely assosciated with the mitochondria [17]. Desmosomes were observed between the granulosa cells and oocyte. ZP deposition began as the follicle cells increased in number and became cuboidal. Numerous oocyte microvilli were observed in the ZP deposits and slender cytoplasmic processes from the granulosa cells traversed the ZP and ended in desmosomes on the oocyte surface. As the follicles grew, the oocyte organelles became located in the cortical ooplasm leaving the central areas of the oocyte nearly devoid of organelles.

\subsubsection{Mouse}

Mouse oocytes from unilaminar follicles (type 1 and 1a), contained nucleoli which were composed of an extensive fibrillogranular network of varying 
electron density [8]. Elongated, round and oval mitochondria were present, most of which contained a single large vacuole. Dumbbell-shaped mitochondria were also observed in these oocytes. The mitochondria were closely associated with the extensive arrays of SER. The Golgi complexes were in close proximity to the ER but had very few, if any, vacuoles indicating they were relatively inactive. Very little RER was found at this stage, or at later stages of oocyte growth, although large numbers of clustered ribosomes were present in the cytoplasm. Plurilaminar follicles (presumably equivalent to the type 2 to 3 stages of follicular development) contained oocytes with more fibrillar and densely compacted nucleoli. The mitochondria were predominantly round or oval and vacuolated and their numbers had increased. The Golgi membranes appeared more active with numerous lipid vesicles in close proximity and the network of ER had begun to break up into more dilated and vesicular tubules. There were fewer clusters of ribosomes and ribosomal lattices became more common.

\subsubsection{Comparison of human and mouse oocyte ultrastructure}

In a comparison of the ultrastructure of human and mouse oocytes at the metaphase I and II stages, Dvorak, 1989 [9] reported that quantitative ultrastructural differences existed between the two species. In particular, large differences in the volume fraction of mitochondria, SER and secondary lysosomes were noted. There were also differences in the types of organelles present: for example, human oocytes contained mitochondria-tubule complexes not seen in the mouse, and the mouse oocytes contained fibrillar structures, lipid droplets and vesicular complexes not seen in the human. 
This highlights the importance of respecting species differences when interpreting results.

A summary of the ultrastructural changes observed during the earliest stages of follicular growth in sheep, cow, human and mouse is shown in Table 2. It should be noted, however, that these studies used different methodologies to compare the different stages of follicular growth.

TABLE 2. Summary of ultrastructural changes during the early stages of follicular growth with respect to four species.

\begin{tabular}{|c|c|}
\hline SPECIES & $\begin{array}{l}\text { FEATURES CHANGING DURING THE EARLIEST STAGES OF } \\
\text { FOLLICULAR GROWTH }\end{array}$ \\
\hline Sheep & $\begin{array}{l}\text { ZP presence, microvillus number, filament number, Golgi } \\
\text { number/location, cortical granule number }\end{array}$ \\
\hline Cow & $\begin{array}{l}\text { nucleus location, nuclei structure, ZP presence, microvillus } \\
\text { number, junction type, coated vesicle number, Golgi } \\
\text { number/location, mitochondria morphology/location, } \\
\text { polyribosome number }\end{array}$ \\
\hline Human & junction number, ZP presence, microvillus number \\
\hline Mouse & $\begin{array}{l}\text { nucleoli structure, Golgi structure, mitochondria } \\
\text { morphology/number, ER structure, ribosome number }\end{array}$ \\
\hline
\end{tabular}




\subsection{Initiation and control of follicular growth}

The primordial follicle is the fundamental developmental unit of the mammalian ovary and these follicles are the source of oocytes for fertilisation during reproductive life. Very little is understood about what causes these primordial follicles to initiate the developmental process towards ovulation. Most of the early research in this area had focussed on the role of the hypothalamic-pituitary-ovarian axis in controlling follicular development, and current technologies developed for contraception and fertility enhancement have arisen from an understanding of this endocrine system [18]. However, in recent years it has become increasingly clear that the oocyte itself also plays an important role in regulating the development of the follicle [19-21]. Coordination of follicular development to ovulation involves a bi-directional communication system between the oocyte and surrounding granulosa cells in addition to the well established system between the ovary and hypothalamic-pituitary axis [20, 22]. However, in mammals, the growth of preantral follicles is now known to occur independently of hormones from the pituitary gland as these follicles continue to develop even after hypophysectomy or in animals where pituitary hormone genes have been inactivated [23, 24].

\subsubsection{Transforming Growth Factor- $\beta$ superfamily}

The transforming growth factor- $\beta$ (TGF- $\beta$ ) superfamily consists of more than 35 proteins including members of the TGF- $\beta$, activin/inhibin, growth and differentiation factor (GDF) and bone morphogenetic protein (BMP) 
subfamilies. These proteins share a similar structure with each being synthesized as a pre-proprotein comprised of a signal peptide, a large proregion, and a smaller biologically active mature region [18]. The TGF- $\beta$ superfamily members signal through two types of membrane-bound serine threonine kinase receptors. Seven type I receptors and five type II receptors have been identified [25]. The TGF- $\beta$ /activin family members typically bind the type II receptor first which then allows binding of the type I receptor. The BMP proteins are generally thought to have a higher affinity for the type I receptor. Binding of the ligand to the first receptor activates a kinase which phosphorylates the second receptor. The phosphorylated kinase of the second receptor activates receptor-regulated Smads (R-Smads). These form complexes with common-partner Smads (Co-Smads), and the R-Smad/CoSmad complexes translocate into the nucleus and regulate the transcription of target genes (Fig 1). BMP type I receptors activate the R-Smads 1, 5 and 8 while activin and TGF- $\beta$ type I receptors activate Smads 2 and 3. Smad 4 acts as a Co-Smad. Other signalling pathways, such as the MAPK family of signalling molecules, may also be involved in mediating the BMP signal transduction pathway.

Genetic mutations in two members of the TGF- $\beta$ superfamily, GDF9 and BMP15, and a TGF- $\beta$ receptor, activin-like kinase 6 (ALK6) also known as BMP receptor type IB, have been shown to have major effects on ovulation rate in sheep [21]. In sheep, GDF9 mRNA and protein are present in the oocytes of type 1 follicles and thereafter to ovulation while BMP15 is first evident in oocytes of type 2 follicles. ALK6 mRNA is present in the oocytes of 
all stages of follicular development in sheep and also in the granulosa cells from the type 2 stage of follicular development. GDF9 has been shown to signal through the type 1 receptor ALK5, and the type II receptor BMPRII, while BMP15 is thought to signal through ALK6 and BMPRII [26]. Other ligands expressed in the follicle also bind the ALK6 receptor and these include BMP2, 4, 6 and 7. ALK6 mRNA is also expressed in the sheep pituitary gland [25].

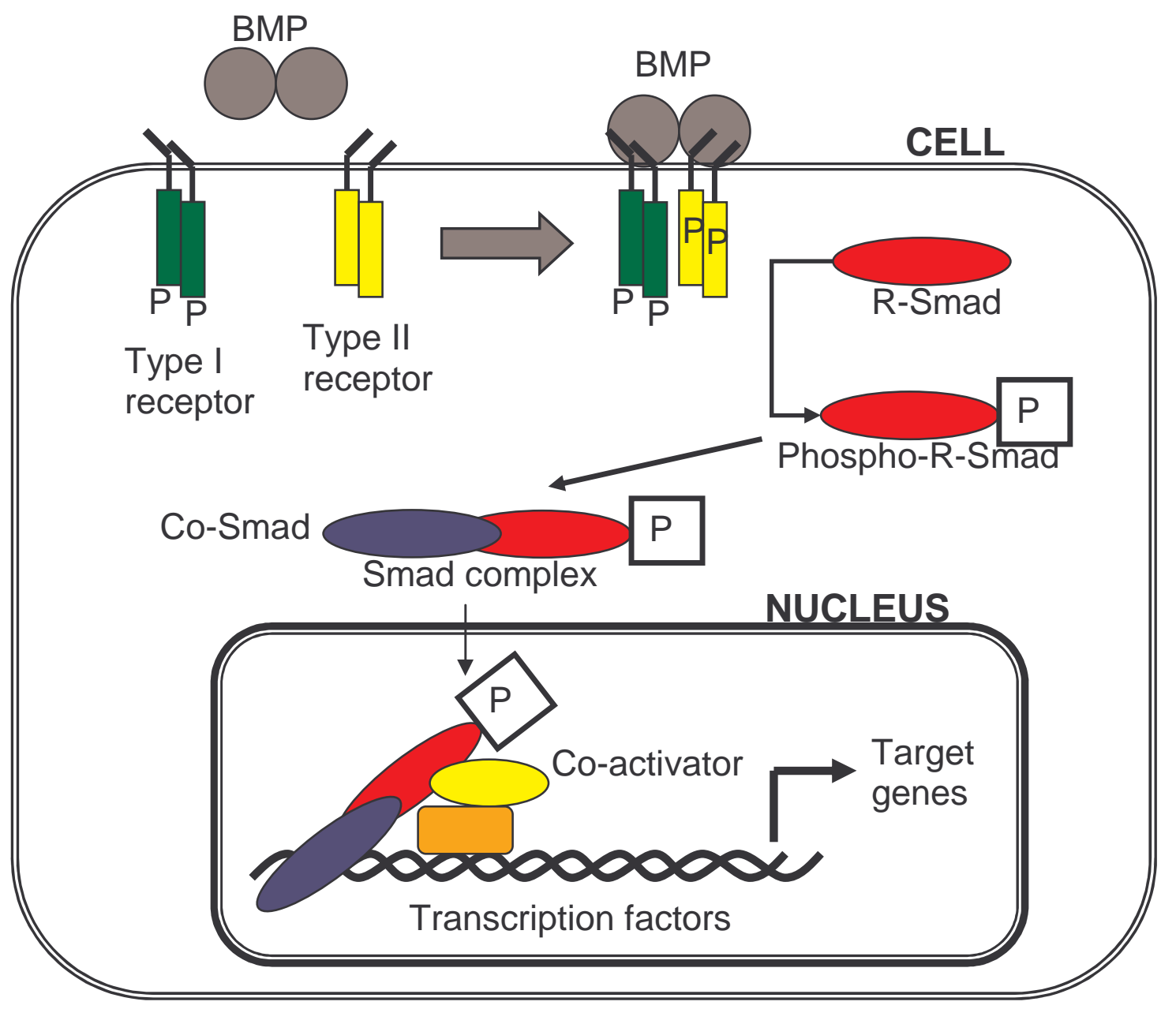

FIGURE 1. BMP/Smad signalling pathway $(\mathrm{P}=$ phosphorylated $)$ 
Ovaries from infertile sheep with homozygous mutations in BMP15 have few, if any, follicles which have developed beyond the type 2 stage while sheep with a heterozygous BMP15 mutation have an increased ovulation rate with significantly more follicles developing to the antral stage [27]. Infertile ewes, homozygous for a mutation in the GDF9 gene, have ovarian follicles which may sometimes develop to the antral stage of growth but most, if not all, have abnormal oocyte morphology and a disorganised array of granulosa cells. As with sheep heterozygous for the BMP15 mutation, those heterozygous for GDF9 have an increased ovulation rate [21]. This is in contrast to findings in mice where BMP15 null animals have normal follicular development, albeit with lower fertility, whereas those heterozygous for a functional BMP15 gene have a normal ovulation rate. Although GDF9 null mice are sterile with follicular development blocked at the primary stage, those heterozygous for a functional GDF9 gene are reported to have normal follicular development and fertility [21].

Oocytes from homozygous GDF9 deficient mice reach a maximum diameter of $80 \mu \mathrm{m}$ within follicles with a mean diameter of $110 \mu \mathrm{m}$ compared to a maximum mean oocyte diameter of $70 \mu \mathrm{m}$ in follicles up to $400 \mu \mathrm{m}$ diameter in control mice [22]. In the absence of GDF9, follicles do not develop past the primary follicular stage to form 2 layers of granulosa cells. However, the ooyctes continue to grow in the absence of proliferating granulosa cells, which is in contrast to that observed in the wild-type or heterozygote. 


\subsubsection{Ultrastructure of GDF9 deficient mice}

Follicles from mice with heterozygous or homozygous mutations in GDF9 were examined by electron microscopy (EM) [22]. The heterozygous GDF9 deficient ovaries showed normal patterns of cell surface organization and organelle density and distribution in full grown oocytes. However, several ultrastructural differences were observed. Multiple Golgi complexes were dispersed in the oocyte cortex but these Golgi lacked the usual stacks of lamellae and consisted of clusters of single lamellae with associated vesicles. The number of cortical granules was less in oocytes from homozygous mutant mice (1.78) compared to oocytes from heterozygous mutant mice (10.2). The lack of cortical granules and well-developed Golgi complexes suggests that late secretory events in oogenesis are compromised in the absence of GDF9. The granulosa cells from GDF9 deficient mice appeared densely packed with extensive areas of adhesive contact throughout the follicle. In comparison, preantral follicles of the heterozygous mouse had loosely organised granulosa cells and cortical microtubules, and only occasionally were focal adhesions observed between the somatic cells.

Transzonal processes (TZPs) are specialised extensions of the granulosa cells that traverse the ZP and terminate on the oocyte surface [28]. They mediate both local delivery of growth factors via gap junctions and possibly facilitate receptor occupation and activation. Oocyte secreted factors such as BMP15 and GDF9 could be transported to granulosa cells via TZPs and be processed for presentation to more distal granulosa cells [27]. The TZPs from granulosa cells in GDF9 deficient follicles appear to be collapsed toward the 
oocyte, disorganised and are fewer in number [22]. The mean +/- s.e.m number of TZPs in oocytes from 3 week old heterozygous deficient mice was $13.1 \pm 0.8 \mathrm{TZPs} / 75 \mu \mathrm{m}^{3}$ and $7.4 \pm 1.0 \mathrm{TZPs} / 75 \mu \mathrm{m}^{3}$ in homozygous GDF9 deficient mice. These results indicate an alteration in the adhesive interactions between granulosa cells and the oocyte in homozygous GDF9 deficient mice.

\subsubsection{ALK6 (BMPRIB) mutation}

Booroola sheep have an increased ovulation rate and an average litter size of one to two extra lambs per copy of the FecB gene (i.e. ALK6 mutation). Animals heterozygous and homozygous for the FecB gene are referred to as $\mathrm{B}+$ and $\mathrm{BB}$ animals respectively. The mutation in ALK6 was identified as a point mutation in a highly conserved region of the intracellular kinase signalling domain [29]. Expression of mRNA encoding ALK6 was observed in oocytes from the type 1 stage of follicular development in both wild type $(++)$ and BB genotypes. Granulosa cells did not express ALK6 mRNA until the type 2 stage of follicular development in the ++ and BB genotypes. Oocytes in the small follicles of BB ewes were larger than in equivalent sized follicles of ++ animals. The oocytes reached a mean diameter of $130.5 \mu \mathrm{m}$ in BB follicles with a mean diameter of $236 \mu \mathrm{m}$ (type 4 follicles) and in ++ follicles with a mean diameter of $383 \mu \mathrm{m}$ (type 5 follicles). Thereafter, the changes in oocyte diameter were similar for both genotypes. Follicles in BB ewes ovulate at a diameter of $\sim 3000 \mu \mathrm{m}$ with a mean number of 1.9 million granulosa cells in the pre-ovulatory follicles. In ++ ewes, the follicles ovulated when they

were between 5000 and $6000 \mu \mathrm{m}$ in diameter with a mean number of $\sim 5$ 
million granulosa cells [30]. Granulosa cells from BB ewes displayed a significantly higher FSH-induced cAMP responsiveness together with an earlier onset of follicular steroidogenesis and LH responsiveness than granulosa cells from ++ animals. The end result of these changes in the ALK6 mutated ewes was that maturation and ovulation of multiple ovarian follicles occured at smaller follicular diameters. It looks likely that the mutation in ALK6 prevents the normal inhibition of granulosa cell differentiation by a BMP [30]. Both the heterozygous BMP15 and the ALK6 mutations caused changes to the oocytes of early preantral follicles and resulted in more rapid follicular maturation and the ovulation of follicles with fewer granulosa cells.

ALK6 (BMPRIB) null mice have prolonged ovulatory cycles, decreased litter size and decreased levels of Cyp19 mRNA (aromatase) in their granulosa cells [31]. This is in contrast to the effect of the FecB mutation in sheep, which exhibited an earlier onset of aromatase activity and increases in both ovulation rate and litter size. There were no obvious abnormalities or differences in the numbers of developing follicles or corpora lutea in ALK6 mutant mice when compared to wild type mice as determined by histology and electron microscopy.

\subsection{Aims of this study}

A thorough understanding of the process of follicular maturation would potentially enable new methods of controlling fertility to be considered. This 
would have implications not only for agricultural practice but also for humans, domestic pets and endangered wild-life species. The changes observed in ovaries from sheep and mice with altered amounts of functional BMP15, GDF9 or ALK6 receptor indicate that these factors are important in controlling follicular development. Animals homozygous for the ALK6 mutation have advanced follicular maturation which is likely to have been initiated during the earliest stages of ovarian follicular growth. Therefore, by quantifying the ultrastructural changes that occur during the early development of sheep ovarian follicles with the ALK6 mutation, a better understanding of the cellular structures that influence early follicular growth might be anticipated. Previous EM studies indicated that important changes during the initial stages of follicular growth include alterations to the number and type of oocytegranulosa cell junctions, an increase in the number of oocyte microvilli and cortical granules, the nucleoli and Golgi structure and the number and form of mitochondria present. The purpose of this study was to focus on the very early stages of follicular development and on possible changes in the volumes and surface areas of sub-cellular structures in relation to changes in the oocyte volume.

In the study by Carabatsos et al., 1998 [22] of GDF9 deficient follicles, a lack of cortical granules and well-developed Golgi complexes was observed indicating a disruption to the secretory processes of the oocyte. The number of TZPs was also reduced indicating an alteration in oocyte-granulosa cell communication. Since the ALK6 receptor is only expressed in granulosa cells from the type 2 stage of follicular development onwards in sheep, it is unlikely 
that any ultrastructural differences will be observed between type 1/1a follicles from ++ and BB ewes. Alteration of the function of ALK6 and the possible inhibition of BMP15 signalling from the oocyte may affect the formation of oocyte-granulosa cell junctions, as seen in GDF9 deficient follicles. An increase in the volume fraction of organelles involved in energy production and membrane synthesis, such as mitochondria, SER and lipid droplets may also be observed at an earlier stage of follicular development in the BB ooctyes to allow for the earlier maturation of these oocytes.

By comparing early development of ovarian follicles from ++ and BB sheep, the role that the ALK6 receptor and its ligand/s play in controlling follicular growth may also be determined.

The aims of this study are:

1) To quantify the ultrastructural changes that occur in the oocyte during the growth of sheep ovarian follicles from the type 1 to the type 3 stages of development.

2) To determine if the ALK6 mutation causes any ultrastructural differences in the oocytes of the early type 1 to 3 stage follicles in BB when compared to ++ animals. 


\section{Materials and Methods}

\section{$2.1 \quad$ Animals}

The procedures carried out to recover the ovaries for this study were performed in accordance with the 1999 Animal Welfare Act Regulations of New Zealand with the approval of the AgResearch Invermay Agricultural Centre Animal Ethics Committee (Appendix 1).

Ovaries were obtained from Romney ewe lambs aged between 26 and 30 days of age that were either homozygous for the ALK6 mutation (BB) $(n=5)$

or non-carriers of the mutation $(++)(n=6)$. New-born lamb ovaries have a very high level of ovarian follicular activity, and the ovaries are small and devoid of extensive connective tissue (K McNatty, unpublished data). Fourweek old lamb ovaries were therefore used for this study to minimise the number of sections needed to be cut to locate small follicles. Genotyping was performed by GenomNZ, AgResearch Invermay Agricultural Centre, Mosgiel, Dunedin. The ++ progeny were sired by five different rams and the BB lambs by 2 different rams. All of the ++ lambs were from twin litters while the litter size of the BB lambs ranged from 2 to 5 . 


\subsection{Fixation \& Processing}

The fixation of the ovaries was performed by glutaraldehyde perfusion in a well ventilated area. To minimise health risks during the fixation procedure, the personnel involved wore half-mask respirators and goggles for protection from the glutaraldehyde fumes. Before euthanasia, a $2 \mathrm{ml}$ injection of Multiparin $5000 \mathrm{IU} / \mathrm{ml}$ heparin sodium (CP Pharmaceuticals Ltd, Wrexham) was given via the jugular vein to prevent clotting. Five minutes after administration of the heparin, euthanasia was induced by an intravenous injection of Pentobarb $500(5 \mathrm{ml})$. After testing for the absence of reflexes, the abdomen was opened by a vertical incision below the sternum and one at right angles to this using a scalpel. The abdominal aorta was exposed below the kidneys using blunt dissection, and a length of linen string was placed under the aorta. A mosquito clamp was used to clamp the aorta above the string. The perfusion apparatus (Fig. 2) was adjusted to allow heparinised saline (Appendix 2) to drip slowly from the tubing to remove the air from the tubing. A small incision was made in the aorta between the clamp and the string, and the end of the perfusion tubing was inserted approximately $2 \mathrm{~cm}$ into the aorta and tied tightly with the string. The femoral arteries and base of the uterus were clamped to restrict the volume of fixative used for the perfusion. The pressure in the perfusion apparatus was increased to between 60 to $80 \mathrm{~mm} \mathrm{Hg}$ using the hand pump, and heparinised saline was perfused into the animal. Incisions were made in the ovarian veins while being careful to avoid cutting the arteries. This allowed blood to flow out of the ovary while the saline perfused through the arteries. When the fluid draining from the 
ovarian veins was clear, the valve on the perfusion apparatus was turned to allow primary fixative (Appendix 2) to perfuse through until the ovaries became yellow in colour and firm to the touch. This process used approximately 300 to $500 \mathrm{ml}$ of heparinised saline and $500 \mathrm{ml}$ of fixative per animal. The saline perfusion began approximately 10 min after euthanasia and the fixative perfusion was completed within 20 to 30 min. Subsequently, both ovaries were removed, weighed and placed into a vial containing the primary fixative. They were then infiltrated with $2 \%(\mathrm{w} / \mathrm{v})$ molten agar at 60 ${ }^{\circ} \mathrm{C}$ for $10 \mathrm{~min}$, transferred to a Petri dish and allowed to solidify at $4{ }^{\circ} \mathrm{C}$ for 5 min. The ovaries were then immersed in primary fixative and cut into slices approximately $1 \mathrm{~mm}$ thick with a razor blade. Antral follicles were dissected out and the remaining ovarian cortex was cut into $1 \mathrm{~mm}$ cubes and transferred into vials containing primary fixative. These remained at $4{ }^{\circ} \mathrm{C}$ for 1 to 2 hours. The ovarian samples were then processed at room temperature according to the regimen described in Table 3. Solution recipes are shown in Appendix 2. 


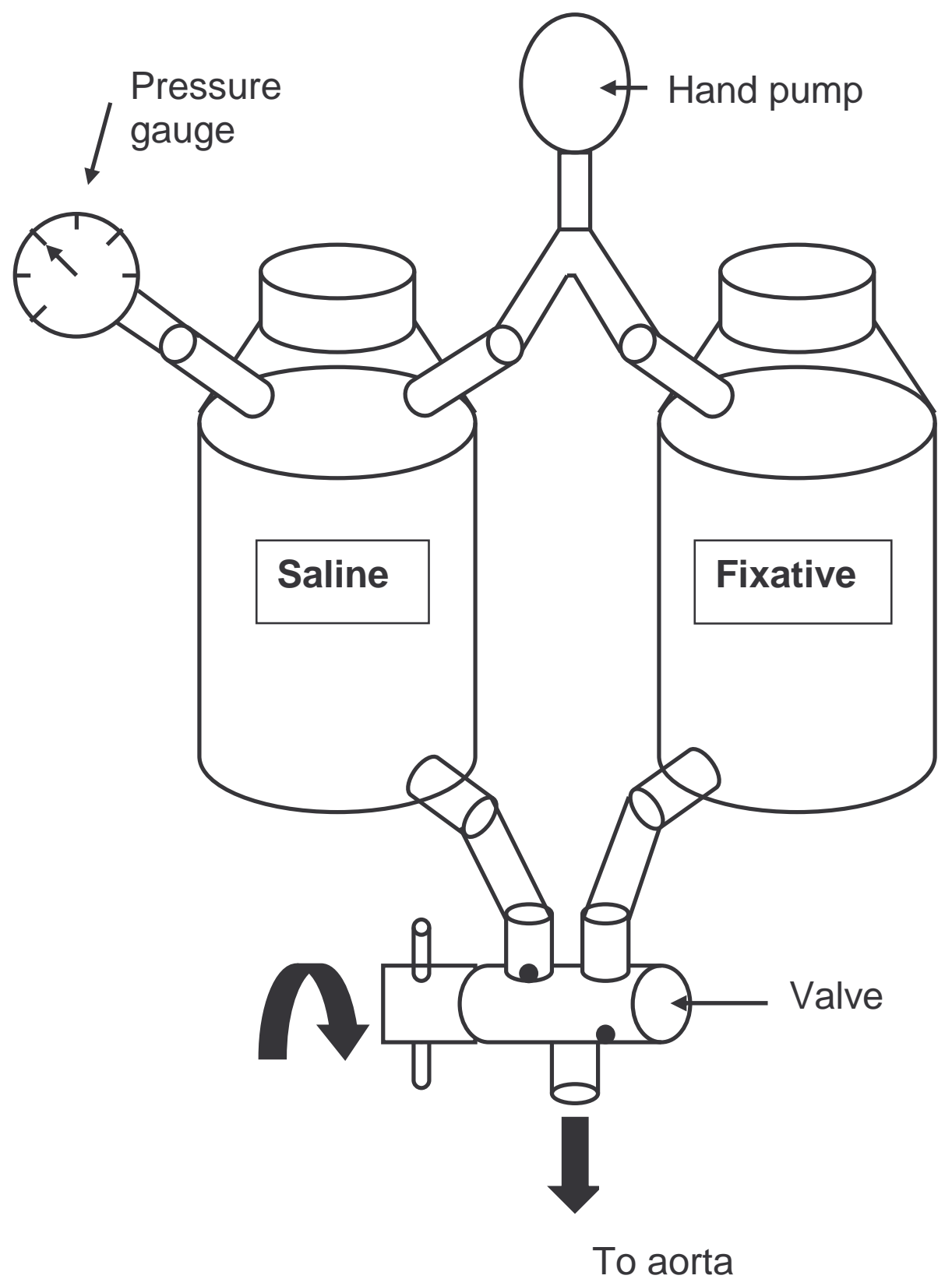

FIGURE 2. Perfusion apparatus 
TABLE 3. Post-fixation tissue processing method.

\begin{tabular}{|l|l|l|}
\hline Procedure & Solution & Time \\
\hline Washed & $0.1 \mathrm{M}$ Sodium cacodylate $(\mathrm{NaCac})$ & $3 \times 10 \mathrm{~min}$ \\
\hline Post-fixed & $1 \%$ Osmium tetroxide in $0.1 \mathrm{M} \mathrm{NaCac}$ & $1 \mathrm{hr}$ \\
\hline Washed & $0.1 \mathrm{M} \mathrm{NaCac}$ & $3 \times 10 \mathrm{~min}$ \\
\hline Washed & Distilled $\mathrm{H}_{2} \mathrm{O}$ & $2 \times 10 \mathrm{~min}$ \\
\hline En bloc stained & $2 \%$ Uranyl acetate in distilled $\mathrm{H}_{2} \mathrm{O}$ & $30 \mathrm{~min}$ \\
\hline Washed & Distilled $\mathrm{H}_{2} \mathrm{O}$ & $10 \mathrm{~min}$ \\
\hline Dehydrated & $50 \%(\mathrm{v} / \mathrm{v})$ ethanol & $10 \mathrm{~min}$ \\
\hline Dehydrated & $70 \%(\mathrm{v} / \mathrm{v})$ ethanol & $15 \mathrm{~min}$ \\
\hline Dehydrated & $95 \%(\mathrm{v} / \mathrm{v})$ ethanol & $15 \mathrm{~min}$ \\
\hline Dehydrated & $100 \%(\mathrm{v} / \mathrm{v})$ ethanol & $3 \times 15 \mathrm{~min}$ \\
\hline Dehydrated & Propylene oxide & $2 \times 20 \mathrm{~min}$ \\
\hline Infiltrated & $1: 1$ Epoxy resin : Propylene oxide & $1.5 \mathrm{hrs}$ \\
\hline Infiltrated & $2: 1$ Epoxy resin : Propylene oxide & $2 \mathrm{hrs}$ \\
\hline Infiltrated & Epoxy resin & overnight \\
\hline Infiltrated & Epoxy resin & $4 \mathrm{hrs}$ \\
\hline Embedded & Epoxy resin & $48 \mathrm{hrs}$ \\
\hline Polymerised & 60 OC & \\
\hline
\end{tabular}




\section{$2.3 \quad$ Sectioning}

Resin blocks from individual animals were selected randomly, and $2 \mu \mathrm{m}$ thick semi-thin sections were cut using a Reichert-Jung 'Ultracut' ultramicrotome and glass knives prepared on an LKB 7800 knife-maker. Sections were mounted on glass slides (Sail Brand, China) and dried on a hot plate. A drop of Richardson's stain (Appendix 2) was placed on the sections and heated for $30 \mathrm{sec}$ on a hot plate then washed under running tap water. The semi-thin sections were viewed with a Nikon YS100 compound microscope using either a $10 x$ or $40 x$ objective. A region of the section through the ovarian cortex containing follicles was selected, and the resin block trimmed with a glass knife to form a trapezoid-shaped block-face approximately $0.1 \mathrm{~mm}$ square containing this region of the cortex. Ultra-thin sections approximately 50 to $70 \mathrm{~nm}$ thick were cut using a Diatome $45^{\circ}$ diamond knife (Biel, Switzerland), and collected onto 200-mesh thin-bar copper grids (ProSciTech, Queensland, Australia). The ultra-thin sections were allowed to dry then stained with uranyl acetate and lead citrate (Appendix 2). Grids were placed on droplets of filtered uranyl acetate on pieces of dental wax (ProSciTech, Queensland, Australia) for $10 \mathrm{~min}$ in a covered Petri dish containing filter paper soaked in $50 \%(\mathrm{v} / \mathrm{v})$ ethanol. The grids were then washed by repeated dipping in a $20 \mathrm{ml}$ vial containing $50 \%(\mathrm{v} / \mathrm{v})$ ethanol, then two vials containing milliQ water, 20 times in each vial. They were air dried and counterstained with lead citrate for $5 \mathrm{~min}$ in a covered Petri dish containing filter paper wetted with $1.0 \mathrm{~N}$ sodium hydroxide. Grids were then washed in three successive vials of boiled, cooled, milliQ water. 


\section{$2.4 \quad$ Light microscopy}

Slides containing semi-thin $(2 \mu \mathrm{m})$ sections were immersed in $100 \%$ xylene for $10 \mathrm{sec}$ and cover-slipped with Depex mounting medium and imaged using an Olympus BX50 compound microscope fitted with an Olympus DP12 digital camera. Images were collected, analysed and stored in a database using Olympus Soft Imaging Solutions (SIS) AnalySIS 5.0 software (Munster, Germany). The oocyte and follicle were assumed to be spherical. Oocyte and follicular diameters for each follicular type were measured on sections through the oocyte nucleus by measuring the maximum oocyte or follicle diameter (a) and the diameter at right angles to this (b). The diameter (D) was calculated using the following equation:

$$
\text { Diameter }(D)(\mu \mathrm{m})=\sqrt{a b}
$$

The follicular classification system used was that reported by Lundy et al., 1999 [1]. All follicles that were sectioned through the nucleus in the semi-thin sections from each animal were measured. Thus, between 15 and 117 type 1 oocytes, 4 to 29 type 2 oocytes and 2 to 5 type 3 oocytes were measured per animal (Appendix 3). Follicles with a single layer of flattened granulosa cells are normally classified as type 1 follicles and those with a mixture of flattened and cuboidal granulosa cells as type 1a follicles. Because $2 \mu \mathrm{m}$ thick nonserial sections were used, it was not possible to exclude the possibility that 
some type 1 follicles would actually be type 1a follicles with cuboidal granulosa cells present in an unobserved area. For this reason, the type 1 and 1a follicles were combined into one group and referred to as type 1 follicles. Moreover, Sawyer et al., 2002 [3] reported that follicles can form either as a type 1 or 1a structure thereby supporting the notion that these were the earliest classes of follicles existing in the sheep ovary. Type 2 follicles consisted of one to less than two complete layers of cuboidal cells, and type 3 follicles had from two to less than four layers of cuboidal granulosa cells. The mean oocyte diameter (D) for each follicular type was calculated for each animal. This was then converted to an oocyte volume using the following equation:

$$
\text { Oocyte volume }\left(\mu \mathrm{m}^{3}\right)=\frac{4 \pi}{3} \times\left(\frac{D}{2}\right)^{3}
$$

\subsection{Transmission electron microscopy}

Ultra-thin sections were examined in either a Philips/FEI CM10 transmission electron microscope (TEM) or a Philips/FEI CM100 TEM at an accelerating voltage of $80 \mathrm{keV}$. Follicles sectioned through the oocyte nucleus were selected, and a low magnification image was recorded of each entire follicle. The follicular profile was sampled by collecting the first image from either 
field 1, 2 or 3 and then every third, fifth or eighth field of view, depending on the size of the follicle, so that a total of between 5 to 10 images were recorded for each follicle (Fig. 3). Follicles still in nests with only one or two granulosa cells associated with the oocyte were excluded from this study as these were believed to be undeveloped and unlikely to grow normally.

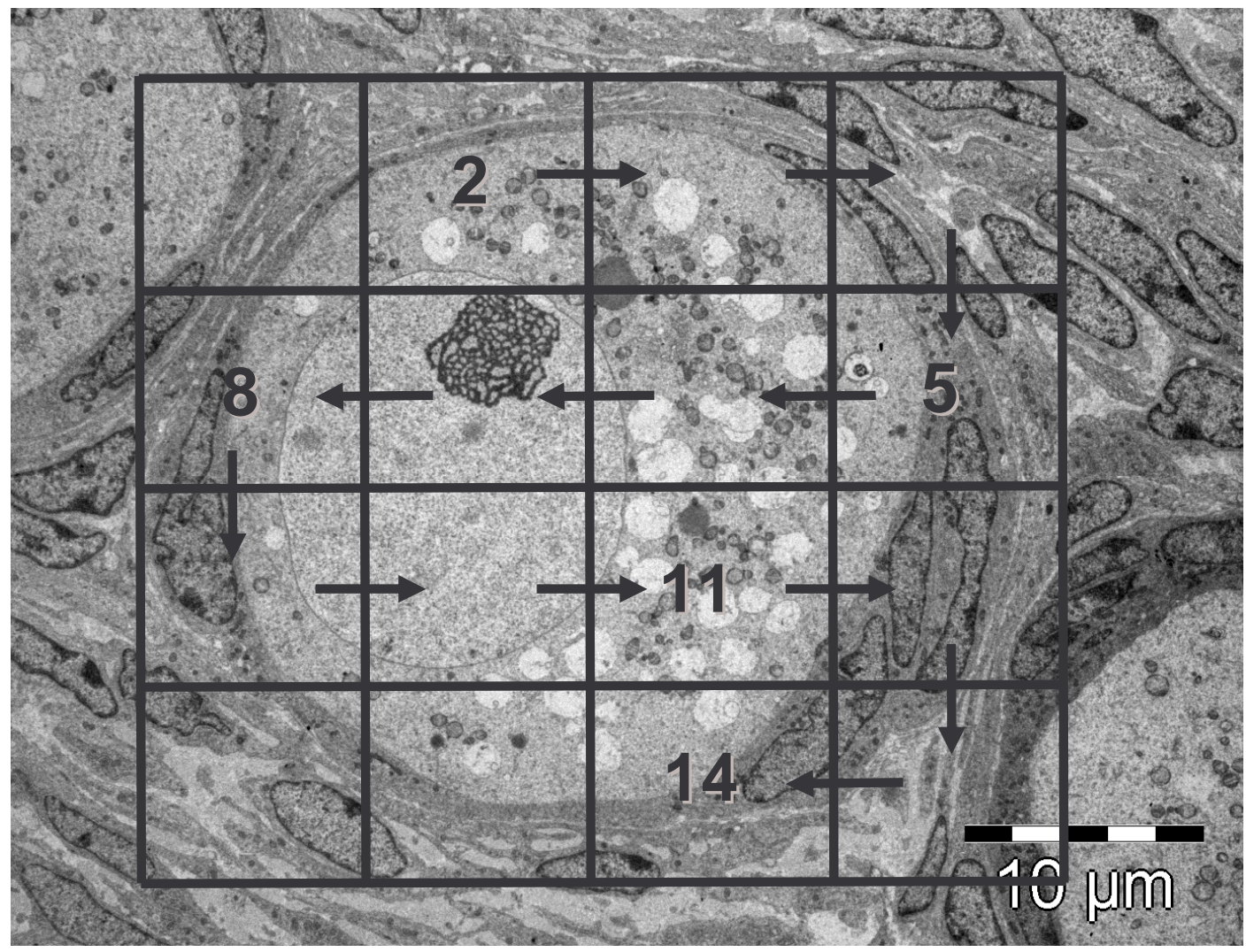

FIGURE 3. TEM sampling method showing entire type 1 follicle with fields of view recorded (numbers).

Images were either recorded on Kodak EM 4489 film or on a SIS MegaView 3 digital camera. Negatives were converted to digital format using an Epson 4990 scanner, and all digital images were saved in tagged image file format 
('.tif'). Images were recorded at a magnification of $8400 \mathrm{x}$ on the CM10 film or $13500 \mathrm{x}$ on the CM100 digital camera. The number of follicles sampled from each animal ranged from 6 to 15 for the type 1 follicles, 4 to 6 for the type 2 follicles and 2 to 5 for the type 3 follicles. All TEM images were stored in a database using analySIS 5.0 software with the images from each follicle being stored in a separate folder.

\subsection{Estimation of cell component volumes and surface areas}

Each image containing any part of the oocyte was used to measure the volumes of SER, Golgi, mitochondria, vesicles, lipid, ribosomes, cortical granules and ZP, and the surface areas of the outer and inner mitochondrial membranes, oocyte membrane, cell junctions and microvilli. To obtain an estimation of the volume of each organelle the volume fraction $\left(V_{v}\right)$ was measured by overlaying the image with a $250 \mathrm{~nm}$ grid. Every grid point on the feature of interest and every point on the oocyte was counted. The numbers of points for every image from a follicle were totalled and the $V_{v}$ calculated from the following formula:

$$
\mathrm{V}_{\mathrm{v}}=\frac{\text { points over object profile }}{\text { total points applied to oocyte }}
$$


The surface density $\left(S_{v}\right)$ of the membranes was measured by overlaying the images with a $500 \mathrm{~nm}$ grid and counting every time the membrane of interest intersected a line. The number of intersections for a particular membrane type from each image from a follicle was totalled and the $S_{v}$ calculated from the following formula:

$$
\begin{aligned}
& \mathrm{S}_{v}=2 \times \frac{I}{L} \\
& (I=\text { no. of intersections, } L=\text { total length of line on oocyte })
\end{aligned}
$$

The $V_{v}$ and $S_{v}$ were then converted to volume or surface area by multiplying by the mean oocyte volume for that follicle type and animal. The number of mitochondria in each image were counted and divided by the area of the oocyte sampled to obtain an estimate of the number of mitochondria per $\mu \mathrm{m}^{2}$ for each follicle. Data for follicles from each animal were averaged and this animal mean data was used in subsequent analyses.

\section{$\underline{2.7 \quad \text { Data analyses }}$}

The data were analysed using Minitab software version 15 (Minitab Pty Ltd, Sydney, Australia). To determine if there was a difference in the birth weight of ++ and BB lambs the mean weights for each genotype were compared by one-way ANOVA. Correlation coefficients between litter size and oocyte 
diameter and between ovarian weight and oocyte diameter were determined using the Pearson correlation coefficient. Differences in the frequency of ZP and cortical granule presence between follicular types and genotypes were determined by $\mathrm{CHI}$-squared analysis. All other data were found not to be normally distributed so a non-parametric Kruskal-Wallis test was used to determine follicular type and genotype differences. 


\section{Results}

\section{$\underline{3.1 \quad \text { Lamb and ovarian weights }}$}

Information about the genotype, litter size, litter sex ratio, birth weight, age and ovarian weights of the lambs used in this study is shown in Table 4. Three of the lambs, tags 436, 97 and 188, had abnormal or absent reproductive tracts and these were excluded from the study.

The mean (s.e.m.) birth weight of the ++ lambs was greater than the BB lambs, $3.77 \mathrm{~kg}(0.29)$ and $2.54 \mathrm{~kg}(0.14)$ respectively $(P=0.006)$. The ++ lambs also had a greater mean (s.e.m.) ovarian weight $0.25 \mathrm{~g}(0.032)$ than the BB lambs $0.078 \mathrm{~g}(0.005)(P<0.0001)$. There was no correlation between litter size and birth weight $(P=0.238)$ or litter size and ovarian weight $(P=0.096)$ 
TABLE 4. Lamb information and ovarian weights with respect to genotype

\begin{tabular}{|c|c|c|c|c|c|c|c|c|}
\hline \multirow[t]{2}{*}{ Tag } & \multirow[t]{2}{*}{ Genotype } & \multirow[t]{2}{*}{$\begin{array}{l}\text { Litter } \\
\text { size }\end{array}$} & \multirow[t]{2}{*}{$\begin{array}{c}\text { Litter } \\
\text { sex ratio } \\
\text { M:F }\end{array}$} & \multirow[t]{2}{*}{$\begin{array}{c}\text { Birth-weight } \\
(\mathrm{kg})\end{array}$} & \multirow[t]{2}{*}{$\begin{array}{l}\text { Age at ovary } \\
\text { recovery (days) }\end{array}$} & \multicolumn{2}{|c|}{$\begin{array}{l}\text { Ovarian weight } \\
\text { (g) }\end{array}$} & \multirow[t]{2}{*}{ notes } \\
\hline & & & & & & left & right & \\
\hline 305 & ++ & 2 & $0: 2$ & 3.6 & 27 & 0.18 & 0.15 & \\
\hline 307 & ++ & 2 & $0: 2$ & 4.0 & 26 & 0.49 & 0.18 & \\
\hline 329 & ++ & 2 & $1: 1$ & 4.1 & 27 & 0.34 & 0.22 & \\
\hline 358 & ++ & 2 & $1: 1$ & 2.4 & 27 & 0.20 & 0.23 & \\
\hline 406 & ++ & 2 & $1: 1$ & 4.3 & 29 & - & - & \\
\hline 410 & ++ & 2 & $0: 2$ & 4.2 & 26 & 0.28 & 0.23 & \\
\hline 436 & ++ & 2 & $1: 1$ & 4.5 & 27 & 1.04 & 0.96 & large ovary phenotype \\
\hline 9 & BB & 2 & $0: 2$ & 2.0 & 28 & - & - & \\
\hline 11 & BB & 3 & $2: 1$ & 2.7 & 30 & 0.06 & 0.06 & \\
\hline 13 & BB & 3 & $1: 2$ & 2.8 & 27 & 0.08 & 0.08 & \\
\hline 97 & BB & 4 & $3: 1$ & 2.6 & 28 & - & - & no uterus or ovaries \\
\hline 185 & BB & 2 & $0: 2$ & 2.7 & 28 & 0.10 & 0.08 & \\
\hline 188 & BB & 4 & $2: 2$ & 3.1 & 27 & 0.12 & 0.10 & no uterus, ovaries abnormal \\
\hline 190 & $\mathrm{BB}$ & 5 & $4: 1$ & 2.5 & 27 & 0.09 & 0.07 & \\
\hline
\end{tabular}




\section{$3.2 \quad$ Follicular types}

At the light microscope (LM) level the oocyte nucleus was randomly located within the cell and many contained nucleoli. The organelles appeared to be evenly distributed throughout the oocyte cytoplasm, and a large proportion of vesicles were visible in the type 1 oocytes. ZP could clearly be seen in the type 3 follicles. All follicles, except two type 3 follicles with pycnotic granulosa cells, appeared to be healthy at the LM level and those that weren't were excluded from the study. Figure 4 shows examples of type 1, 1a, 2 and 3 follicles.
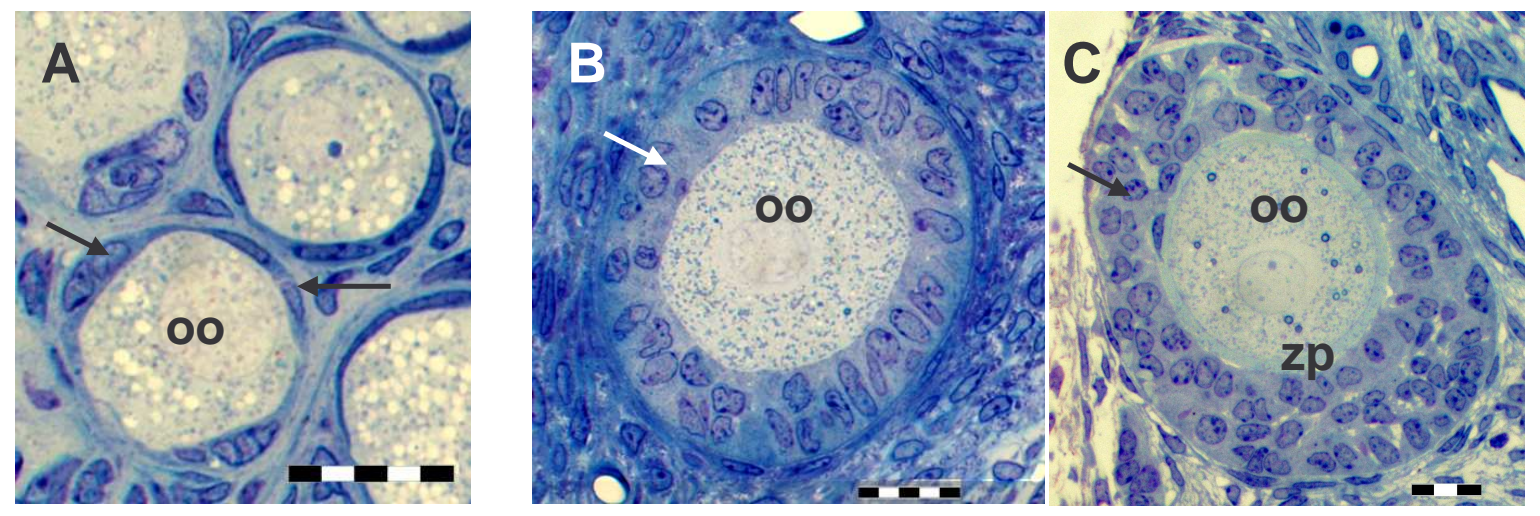

FIGURE 4. LM images of follicles of ++ animals showing A) type 1 and $1 \mathrm{a}$ follicles where the oocyte (0o) is surrounded by a single layer of flattened, or a mixture of flattened and cuboidal granulosa cells (arrows); B) a type 2 follicle with one and a half layers of cuboidal granulosa cells and $\mathbf{C}$ ) a type 3 follicle with between 2 and less than 4 layers of cuboidal granulosa cells and a complete layer of zona pellucida (zp). Bar $=20 \mu \mathrm{m}$ 
A lower percentage of type 1 follicles and a higher percentage of type 2 follicles were observed in the BB ovarian sections compared to the ++ sections, whereas the type $1 \mathrm{a}$ and 3 follicles were present in similar proportions between genotypes (Table 5).

TABLE 5. Percentage of each follicular type with respect to genotype ( $\mathrm{n}=$ number of follicles measured)

\begin{tabular}{|c|c|c|}
\hline \multirow{2}{*}{ Follicular Type } & ++ & BB \\
\hline 1 & $35.2(137)$ & $18.2(64)$ \\
\hline $1 a$ & $48.1(187)$ & $52.0(183)$ \\
\hline 2 & $11.8(46)$ & $24.1(85)$ \\
\hline 3 & $4.9(19)$ & $5.7(20)$ \\
\hline
\end{tabular}

\subsection{Oocyte diameter}

The mean oocyte diameter data for each animal and follicular type are shown in Appendix 3. The mean oocyte diameter of type 1 follicles was greater in BB animals than ++ animals $(P=0.006)$, while the type 2 and 3 mean oocyte diameters were not significantly different between the genotypes (Table 6). When type 1 and 1a oocyte diameters were analysed separately, the oocytes of BB animals were significantly larger than the ++ animals for both follicular types $(P<0.05)$ (Table 7$)$. There was no correlation between litter size and oocyte diameter for each follicular type, $P=0.242,0.105$ and 0.809 for type 
1, 2 and 3 follicles respectively. However, there appeared to be a correlation between ovarian weight and oocyte diameter which was negative for type 1 follicles and positive for type 2 follicles, although this was not statistically significant $(P=0.052$ and 0.053 respectively) (Fig 5). There was no correlation between ovarian weight and oocyte diameter in the type 3 follicles $(P=0.481)$. When the genotypes were analysed separately there were no correlations between any of these variables.

TABLE 6. Mean (s.e.m.) oocyte diameter, $\mu \mathrm{m}$, with respect to follicular type and genotype

\begin{tabular}{|c|c|c|}
\hline Follicular Type & ++ & BB \\
\hline Type 1 & $27.05(0.30)$ & $29.76(0.58)^{\star *}$ \\
\hline Type 2 & $40.21(1.76)$ & $36.82(1.13)$ \\
\hline Type 3 & $68.05(1.30)$ & $71.79(2.30)$ \\
\hline
\end{tabular}

Asterisks indicate significant differences between genotypes and within follicular types. ${ }^{*} P<0.01$

TABLE 7. Mean (s.e.m.) oocyte diameter, $\mu \mathrm{m}$, of type 1 and 1a follicular types with respect to genotype

\begin{tabular}{|c|c|c|}
\hline Follicular Type & ++ & BB \\
\hline Type 1 & $25.78(0.28)$ & $27.80(0.39)$ * \\
\hline Type 1a & $28.06(0.53)$ & $30.32(0.58)$ * \\
\hline
\end{tabular}

Asterisks indicate significant difference between genotypes and within follicular types. ${ }^{*} P<0.05$ 


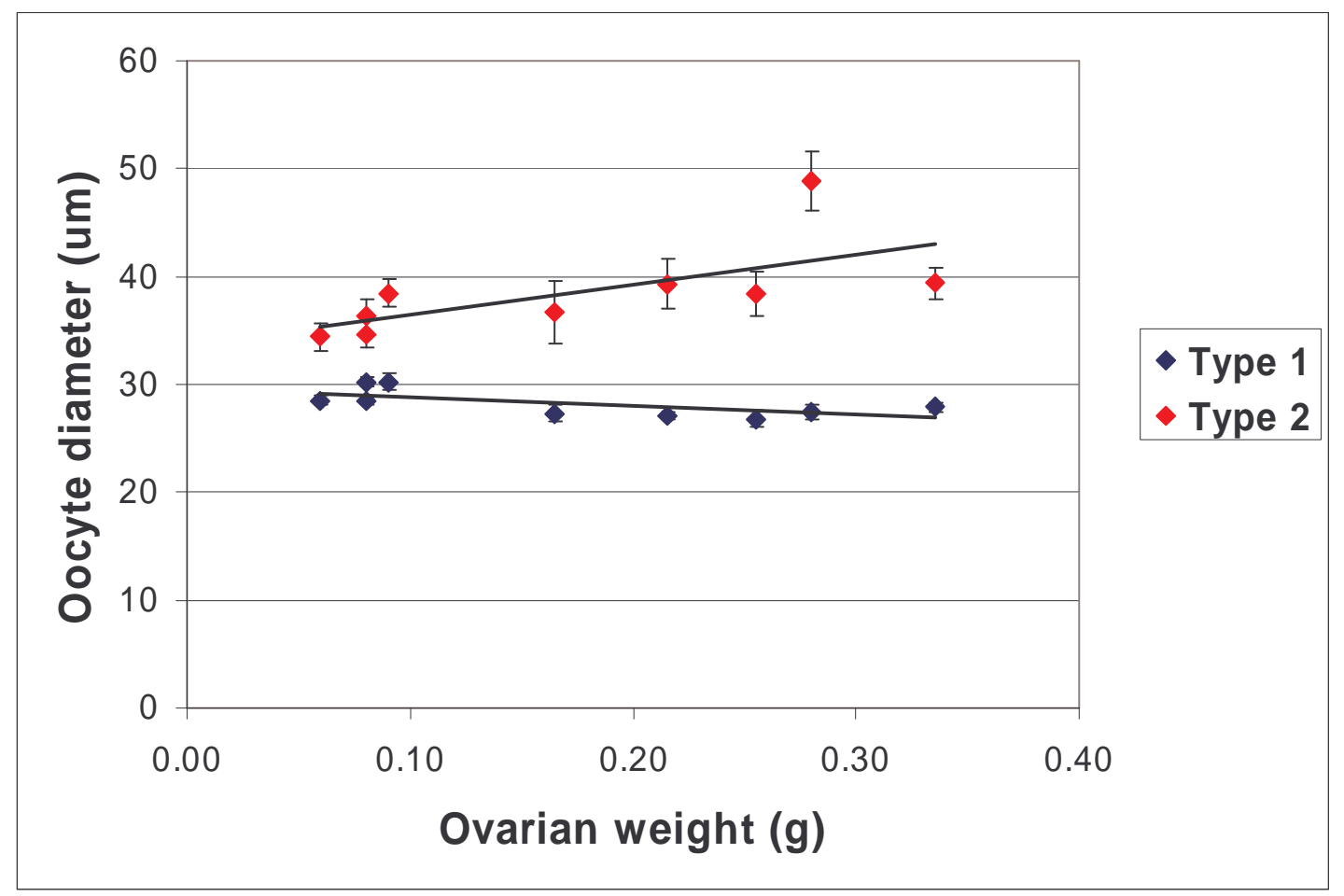

FIGURE 5. Correlation between ovarian weight (g) and oocyte diameter $(\mu \mathrm{m})$ in type 1 and 2 follicles

\subsection{General ultrastructure}

In all follicular types the oocyte nucleus was either centrally or eccentrically located, and most of the organelles were evenly distributed throughout the cytoplasm (Figs 6 \& 7A). Chromatin in the oocyte nuclei of all follicles examined was present as euchromatin, and most sections contained a reticulated nucleolus indicating that both active gene transcription and ribosomal RNA synthesis were occurring in these cells. Pores were also observed in the nuclear membrane (Fig 7B). SER was abundant but RER was only observed occasionally and usually only in the oocytes of type 3 
follicles. Free ribosomes were present in the cytoplasm of all follicular types and Golgi complexes were observed in most sections. The mitochondria were predominantly round with arched cristae but a few were elongated with transverse cristae, and most were closely associated with SER (Fig 8). Vesicles were most abundant in the type 1 follicles. Lipid droplets were observed in most oocytes but the amount varied between follicles and follicular types and they were often surrounded by SER (Fig 8A). In a few oocytes, mitochondria were seen to be in close contact with lipid droplets (Fig 9A). Cortical granules were more commonly seen in the type 3 follicles and were located towards the oocyte periphery (Fig 9B). Junctions between the oocyte and granulosa cells were zonula adherens type connections (Fig 10A). Once a layer of ZP had formed, junctions were observed between the oolemma and the ends of granulosa cell processes that extended across the ZP (Fig 10B). Microvilli were present in all follicles, but appeared to increase in number and length as ZP volume increased (Figs 8B \& 9B). 

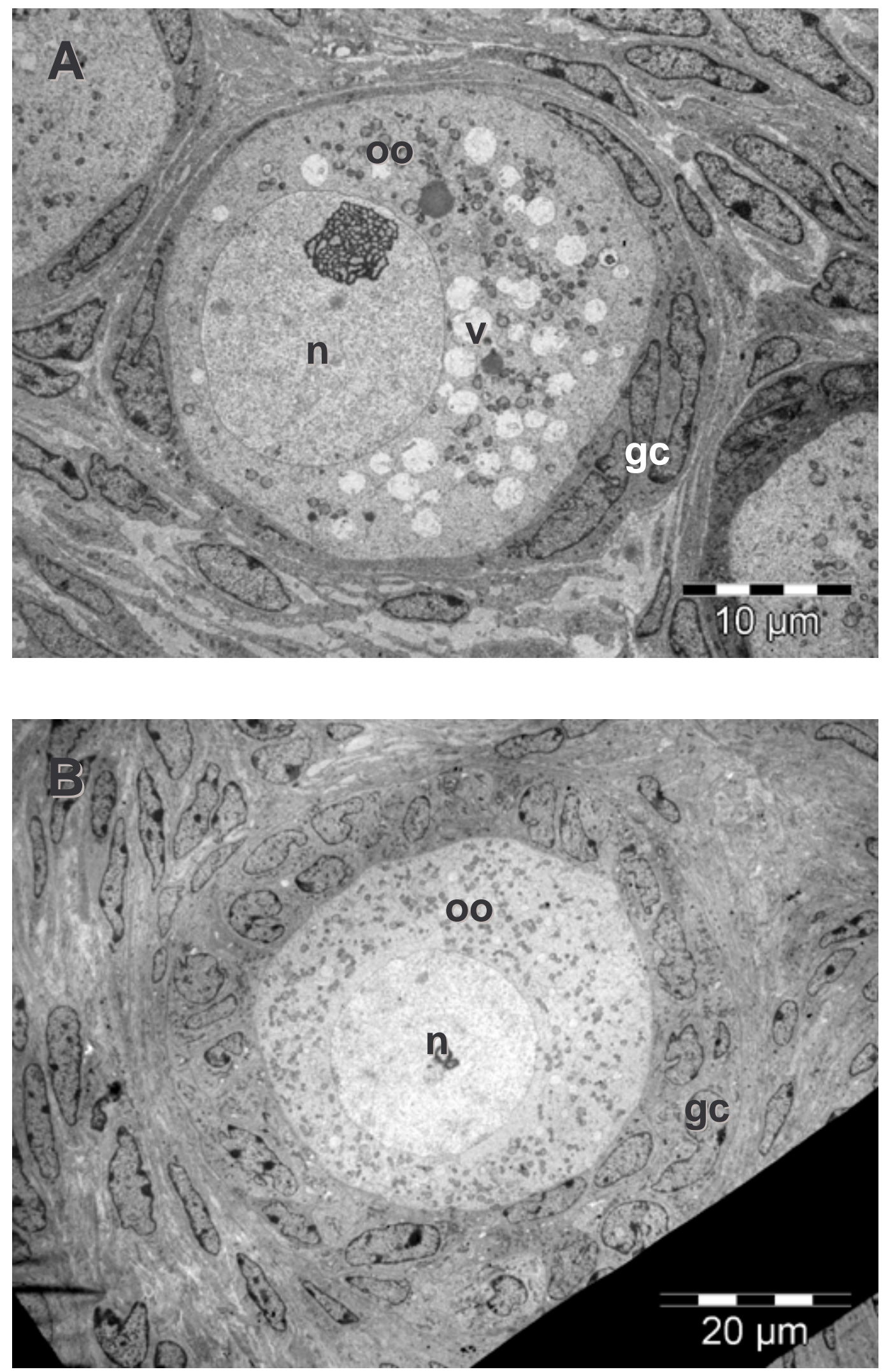

FIGURE 6. Transmission electron micrographs of $\mathbf{A}$ ) type 1 follicle with eccentrically located nucleus and numerous vesicles in cytoplasm, and B) type 2 follicle with organelles evenly distributed throughout oocyte cytoplasm; oocyte (oo), granulosa cells (gc), nucleus (n), vesicles (v). 

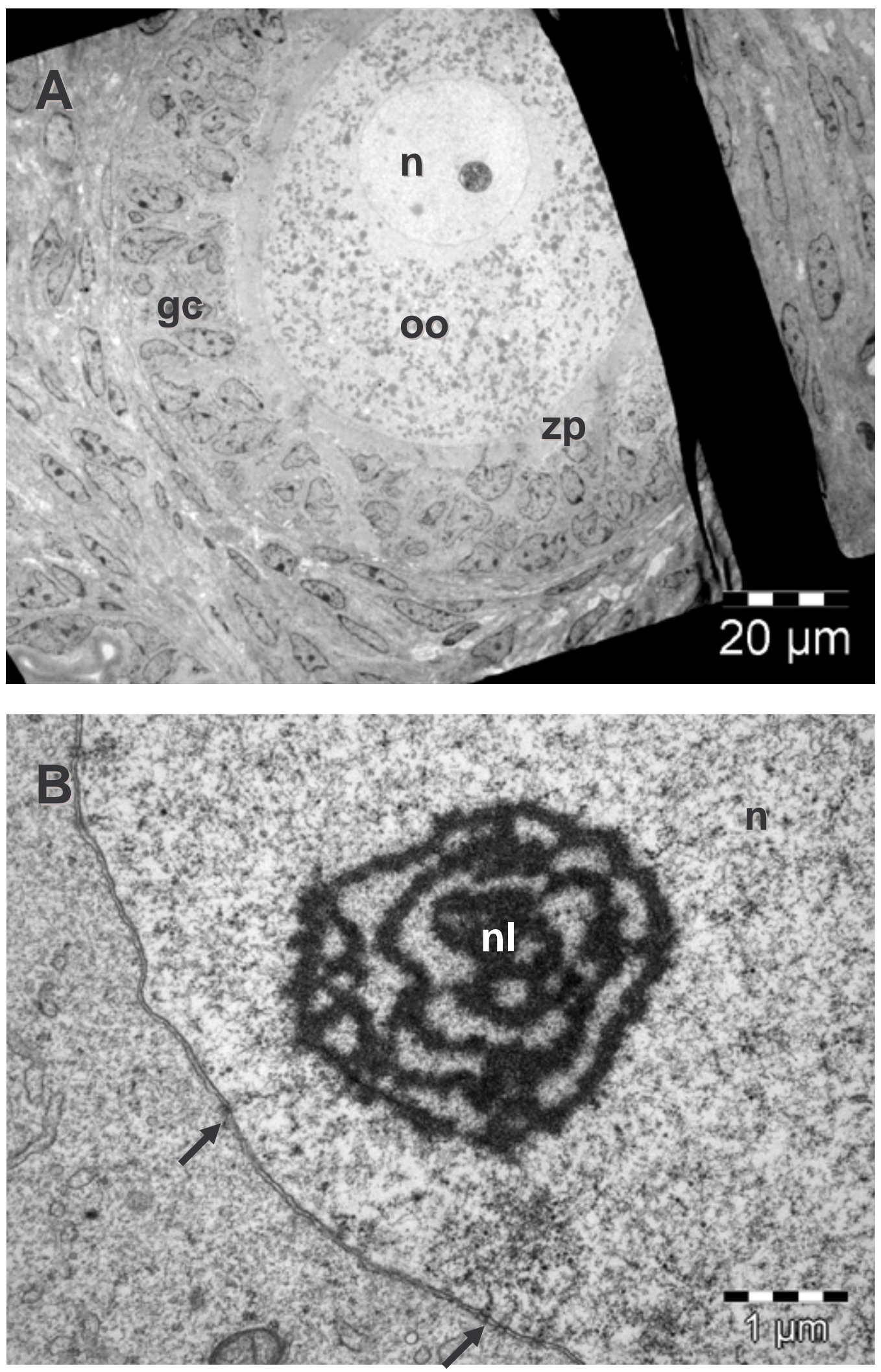

FIGURE 7. Transmission electron micrographs of $\mathbf{A}$ ) type 3 follicle with evenly distributed oocyte organelles and a complete layer of ZP, and B) part of an oocyte nucleus showing nucleopores (arrows), decondensed chromatin and a nucleolus. Oocyte (oo), granulosa cells (gc), zona pellucida (zp), nucleus $(\mathrm{n})$, nucleolus $(\mathrm{nl})$. 

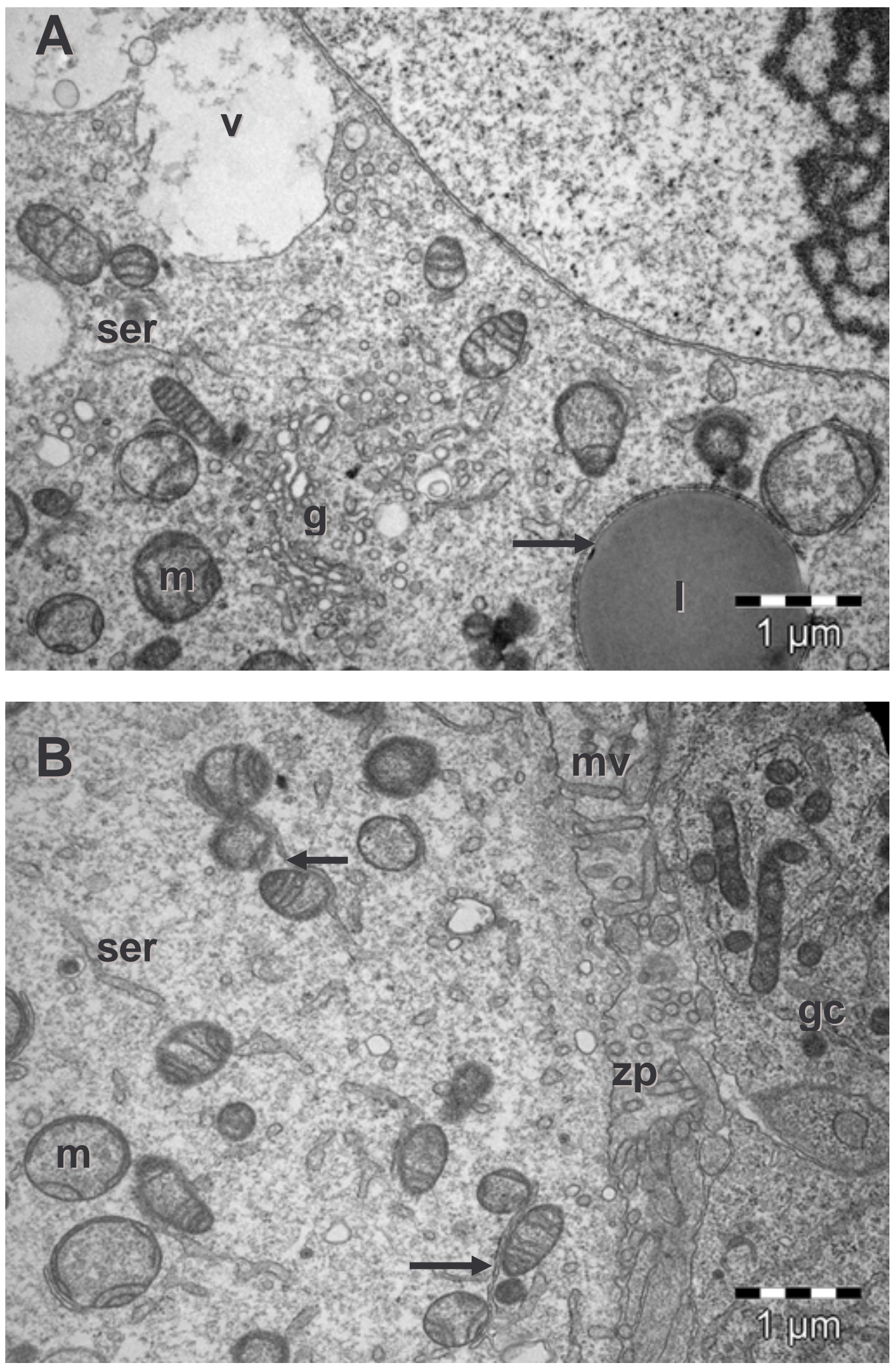

FIGURE 8. Transmission electron micrographs of type 2 follicles showing A) part of oocyte containing SER (ser), mitochondria (m), lipid (I), Golgi (g) and vesicles (v), and B) edge of oocyte with microvilli (mv) extending into zona pellucida (zp) and granulosa cells (gc). SER can be seen in close contact with lipid and mitochondria (arrows). 

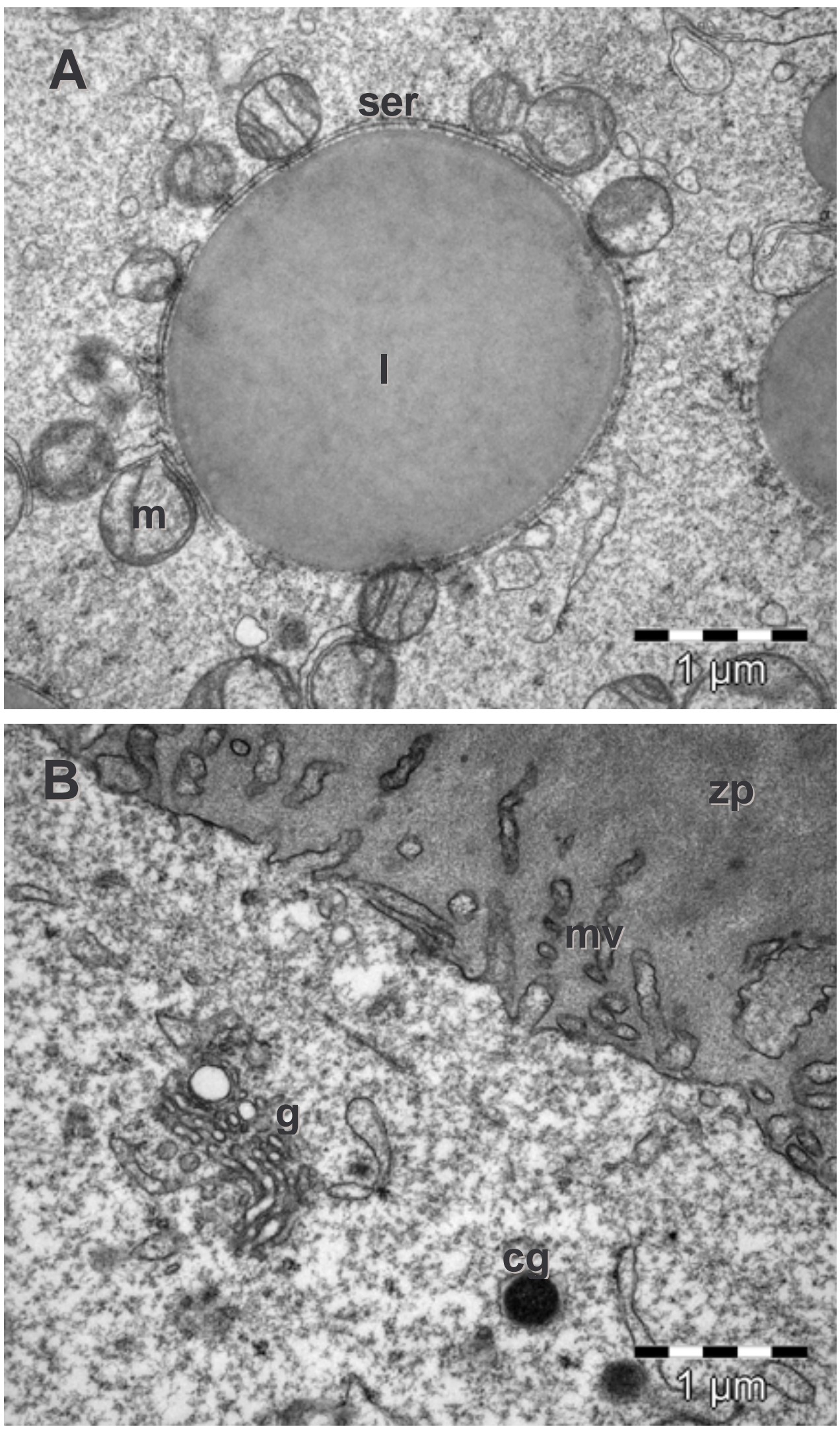

FIGURE 9. Transmission electron micrographs of $\mathbf{A}$ ) lipid droplet (I) interacting with SER (ser) and mitochondria ( $\mathrm{m}$ ), and B) outer edge of oocyte from a type 3 follicle containing a Golgi complex (g), cortical granule (cg) and showing microvilli (mv) extending into the ZP (zp). 

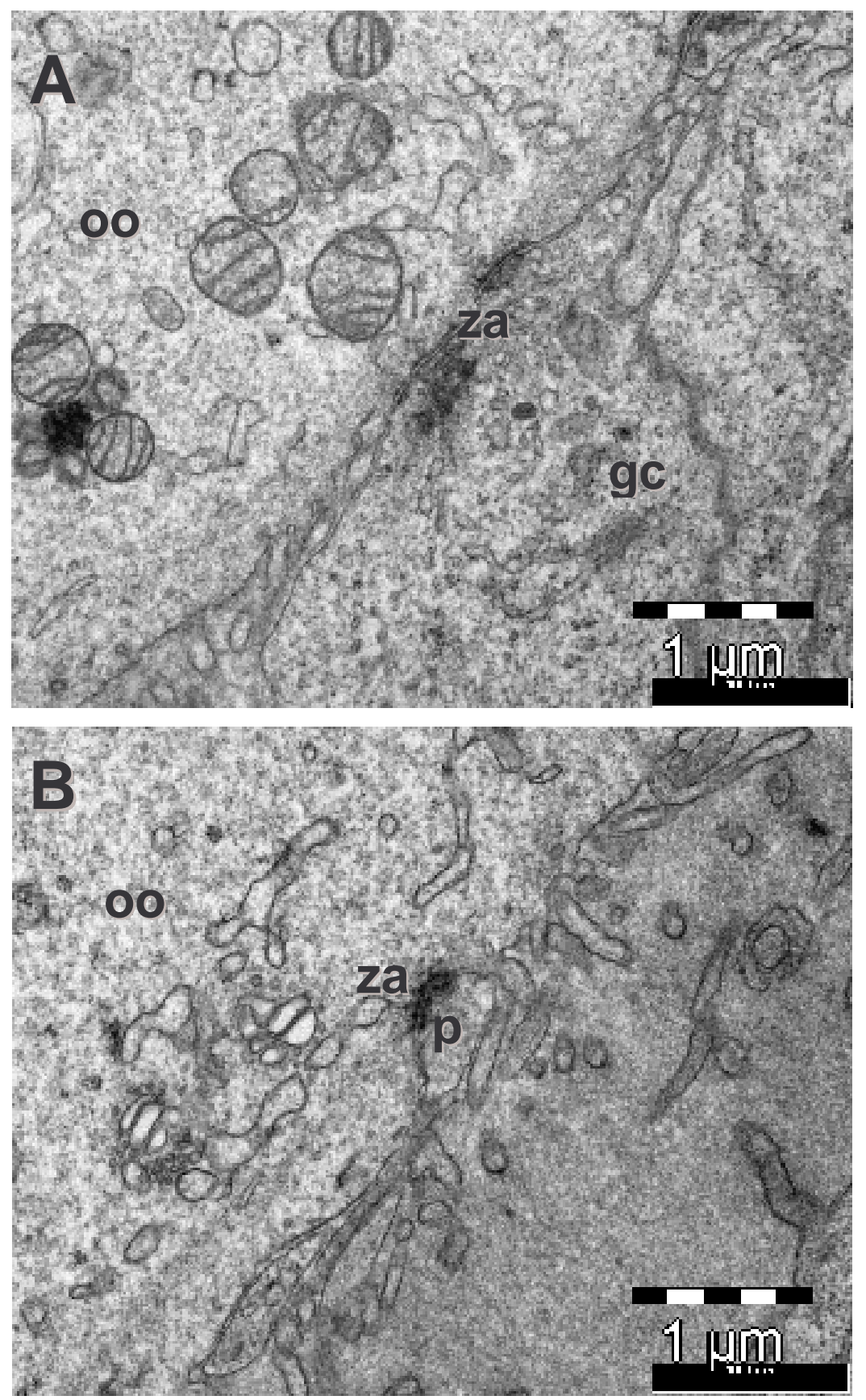

FIGURE 10. Transmission electron micrographs showing A) type 2 follicle with zonula adherens type junctions (za) between the oocyte (0o) and granulosa cells (gc), and B) type 3 follicle showing zonula adherens junction between a granulosa cell process $(p)$ and oocyte (oo). 


\subsection{Volume fractions and surface densities of oocyte structures}

\subsubsection{Changes with follicular type}

As follicles grew from the type 1 to the type 2 stage of development in the ++ ovary, the $V_{v}$ of the mitochondria, lipid and ZP in the oocyte increased whereas that for the vesicles decreased $(P<0.05)$ (Table 8). The $S_{v}$ of the outer and inner mitochondrial membranes was noted to increase $(P<0.05)$ (Table 9). The $V_{v}$ of the SER, vesicles and lipid in the oocyte decreased as follicles developed from the type 2 to the type 3 stages (Table 8 ). Cortical granules (CG), ZP and microvilli all exhibited an increase in either $V_{v}$ or $S_{v}$ during this stage of development $(P<0.05)$ (Tables $8 \& 9)$. The $V_{v}$ of the Golgi in oocytes was less in the type 3 compared to the type 1 follicle $(P<$ 0.05) (Table 8). Mitochondrial number per area of oocyte increased from the type 1 to type 2 follicles and then remained the same in the type 3 follicles (Table 8).

\subsubsection{Differences between genotypes}

In oocytes of type 1 follicles, the $V_{v}$ or $S_{v}$ of mitochondria, ZP, outer mitochondrial membrane, oocyte membrane and junctional complexes were all greater in follicles from the BB compared to the ++ genotype whereas the $\mathrm{V}_{\mathrm{v}}$ of vesicles was less in the BB compared to ++ animals $(P<0.05)$. At the type 1 stage of development, the mitochondrial number per area of oocyte sampled was greater in the follicles of BB than ++ animals (Tables $8 \& 9$ ). At the type 2 stage of development, there were no significant differences in the $V_{v}$ or $S_{v}$ of any structures within the oocytes when comparing genotypes. At 
the type 3 stage, the only difference noted was a greater $V_{v}$ of ribosomes in oocytes from BB compared to ++ animals $(P<0.05)$ (Tables $8 \& 9)$.

\subsection{Volumes and surface areas}

\subsubsection{Changes with follicular type}

As the follicles developed from the type 1 through to the type 3 stage, the

volume and surface areas of all sub-cellular structures measured within oocytes increased $(P<0.05)$. The volumes of the Golgi, vesicles and cortical granules in oocytes were not found to change until the follicle developed from the type 2 to the type 3 stage (Tables $10 \& 11$ ).

\subsubsection{Differences between genotypes}

At the type 1 stage of development, oocytes in BB animals had a greater volume of SER and ZP, a greater surface area of junctional complexes with granulosa cells and a greater volume and surface area of mitochondria and outer mitochondrial membranes than oocytes from the ++ genotype $(P<$ 0.01) (Tables $10 \& 11$ ). The oocyte membrane in type 1 follicles from the BB genotype also had a greater surface area which was not unexpected since the oocyte volume was greater compared to type 1 follicles in ++ animals. The only structure that differed significantly between the genotypes at the type 2 stage was the lipid volume which was greater in oocytes from the ++ genotype $(P<0.05)$ (Table 10). At the type 3 stage of development, the 
ribosomal volume was greater in oocytes from the BB animals $(P<0.05)$ but all other structures were similar between the genotypes (Tables 10 \& 11).

\subsection{Zona pellucida and cortical granules}

Table 12 shows the percentage of follicles that had ZP and cortical granules present with respect to follicular type and genotype. The percentage of follicles in which ZP and cortical granules (CG) were observed increased with each stage of development $(P<0.05)$. ZP was present in a greater percentage of type 1 follicles of BB when compared to ++ animals $(P<$ 0.001), while at the type 2 and 3 stages there were no significant differences between genotypes. At the type 1 and 2 stages of follicular development, the percentage of oocytes containing cortical granules in BB animals appeared to be greater than in ++ animals, but this was not significantly different. 
TABLE 8. Mean (s.e.m.) volume fraction $\left(\mathrm{V}_{\mathrm{v}}\right)$ of oocyte structures for each follicular type and genotype

\begin{tabular}{|c|c|c|c|c|c|c|c|c|c|c|}
\hline $\begin{array}{l}\text { Fol. } \\
\text { Type }\end{array}$ & $\begin{array}{l}\text { Geno } \\
\text {-type }\end{array}$ & SER & Golgi & Mitochondria & Vesicles & Lipid & ZP & CG & Ribosomes & Mito $/ \mu m^{2}$ \\
\hline 1 & ++ & $\begin{array}{c}0.0479^{a} \\
(0.0023)\end{array}$ & $\begin{array}{c}0.0120^{a} \\
(0.0024)\end{array}$ & $\begin{array}{c}0.0614^{a} \\
(0.0027)\end{array}$ & $\begin{array}{c}0.0758^{a} \\
(0.0091)\end{array}$ & $\begin{array}{c}0.0075^{a} \\
(0.0022)\end{array}$ & $\begin{array}{c}0.0000^{a} \\
(0.0000)\end{array}$ & $\begin{array}{c}0.00002^{a} \\
(0.00001)\end{array}$ & $\begin{array}{l}0.0040 \\
(0.0005)\end{array}$ & $\begin{array}{c}0.0676^{a} \\
(0.0034)\end{array}$ \\
\hline 1 & BB & $\begin{array}{l}0.0489 \\
(0.0019)\end{array}$ & $\begin{array}{l}0.0078 \\
(0.0011)\end{array}$ & $\begin{array}{c}0.0732 \text { * } \\
(0.0036)\end{array}$ & $\begin{array}{c}0.0465 * \\
(0.0094)\end{array}$ & $\begin{array}{l}0.0066 \\
(0.0019)\end{array}$ & $\begin{array}{l}0.0024 \text { * } \\
(0.0019)\end{array}$ & $\begin{array}{l}0.00027 \\
(0.00019)\end{array}$ & $\begin{array}{l}0.0023 \\
(0.0003)\end{array}$ & $\begin{array}{c}0.0863 \text { * } \\
(0.0052)\end{array}$ \\
\hline 2 & ++ & $\begin{array}{c}0.0448^{a} \\
(0.0028)\end{array}$ & $\begin{array}{c}0.0077^{a, b} \\
(0.0020)\end{array}$ & $\begin{array}{l}0.0848^{b} \\
(0.0035)\end{array}$ & $\begin{array}{c}0.03366^{b} \\
(0.0035)\end{array}$ & $\begin{array}{l}0.0203^{b} \\
(0.0048)\end{array}$ & $\begin{array}{c}0.0140 \mathrm{~b} \\
(0.0054)\end{array}$ & $\begin{array}{c}0.00007^{a} \\
(0.00004)\end{array}$ & $\begin{array}{l}0.0034 \\
(0.0003)\end{array}$ & $\begin{array}{l}0.0991^{b} \\
(0.0073)\end{array}$ \\
\hline 2 & BB & $\begin{array}{l}0.0430 \\
(0.0046)\end{array}$ & $\begin{array}{l}0.0089 \\
(0.0017)\end{array}$ & $\begin{array}{l}0.0838 \\
(0.0066)\end{array}$ & $\begin{array}{l}0.0340 \\
(0.0075)\end{array}$ & $\begin{array}{l}0.0101 \\
(0.0017)\end{array}$ & $\begin{array}{l}0.0264 \\
(0.0091)\end{array}$ & $\begin{array}{l}0.00046 \\
(0.00020)\end{array}$ & $\begin{array}{l}0.0050 \\
(0.0006)\end{array}$ & $\begin{array}{c}0.1015 \\
(0.0061)\end{array}$ \\
\hline 3 & ++ & $\begin{array}{c}0.0312^{b} \\
(0.0025)\end{array}$ & $\begin{array}{c}0.0063^{b, c} \\
(0.0013)\end{array}$ & $\begin{array}{c}0.0679^{a, b} \\
(0.0070)\end{array}$ & $\begin{array}{c}0.0177^{c} \\
(0.0027)\end{array}$ & $\begin{array}{c}0.0088^{a, c} \\
(0.0020)\end{array}$ & $\begin{array}{c}0.1558^{c} \\
(0.0250)\end{array}$ & $\begin{array}{c}0.00083^{b} \\
(0.00024)\end{array}$ & $\begin{array}{l}0.0039 \\
(0.0003)\end{array}$ & $\begin{array}{c}0.0949^{b} \\
(0.0079)\end{array}$ \\
\hline 3 & BB & $\begin{array}{l}0.0283 \\
(0.0031)\end{array}$ & $\begin{array}{l}0.0071 \\
(0.0017)\end{array}$ & $\begin{array}{l}0.0671 \\
(0.0037)\end{array}$ & $\begin{array}{l}0.0192 \\
(0.0034)\end{array}$ & $\begin{array}{l}0.0050 \\
(0.0011)\end{array}$ & $\begin{array}{l}0.1284 \\
(0.0245)\end{array}$ & $\begin{array}{l}0.00171 \\
(0.00046)\end{array}$ & $\begin{array}{c}0.0059 \text { * } \\
(0.0006)\end{array}$ & $\begin{array}{l}0.0866 \\
(0.0081)\end{array}$ \\
\hline
\end{tabular}

Letters indicate differences between ++ follicular types $P<0.05$

Asterisks indicate differences between genotypes within a follicular type $P<0.05$ 
TABLE 9. Mean (s.e.m.) surface density $\left(S_{v}\right)$ of oocyte structures for each follicular type and genotype

\begin{tabular}{|c|c|c|c|c|c|c|}
\hline $\begin{array}{c}\text { Follicular } \\
\text { Type }\end{array}$ & Genotype & $\begin{array}{c}\text { Outer } \\
\text { Mitochondrial } \\
\text { Membrane }\end{array}$ & $\begin{array}{c}\text { Inner } \\
\text { Mitochondrial } \\
\text { Membrane }\end{array}$ & $\begin{array}{c}\text { Oocyte } \\
\text { Membrane }\end{array}$ & Junctions & Microvilli \\
\hline 1 & ++ & $\begin{array}{c}0.4964^{\mathrm{a}} \\
(0.0219)\end{array}$ & $\begin{array}{c}0.2716^{\mathrm{a}} \\
(0.0235)\end{array}$ & $\begin{array}{c}0.3399 \\
(0.0239)\end{array}$ & $\begin{array}{c}0.0031 \\
(0.0009)\end{array}$ & $\begin{array}{c}0.1292^{\mathrm{a}} \\
(0.0156)\end{array}$ \\
\hline 1 & BB & $\begin{array}{c}0.6109^{*} \\
(0.0268)\end{array}$ & $\begin{array}{c}0.2930 \\
(0.0250)\end{array}$ & $\begin{array}{c}0.3532 \\
(0.0238)\end{array}$ & $\begin{array}{c}0.0064^{*} \\
(0.0010)\end{array}$ & $\begin{array}{c}0.1305 \\
(0.0190)\end{array}$ \\
\hline 2 & ++ & $\begin{array}{c}0.7399^{\mathrm{b}} \\
(0.0456)\end{array}$ & $\begin{array}{c}0.3745^{\mathrm{b}} \\
(0.0205)\end{array}$ & $\begin{array}{c}0.2960 \\
(0.0189)\end{array}$ & $\begin{array}{c}0.0051 \\
(0.0007)\end{array}$ & $\begin{array}{c}0.1420^{\mathrm{a}} \\
(0.0190)\end{array}$ \\
\hline 2 & BB & $\begin{array}{c}0.7520 \\
(0.0387)\end{array}$ & $\begin{array}{c}0.3724 \\
(0.0407)\end{array}$ & $\begin{array}{c}0.3041 \\
(0.0239)\end{array}$ & $\begin{array}{c}0.0060 \\
(0.0013)\end{array}$ & $\begin{array}{c}0.1506 \\
(0.0220)\end{array}$ \\
\hline 3 & ++ & $\begin{array}{c}0.6693^{\mathrm{b}} \\
(0.0477)\end{array}$ & $\begin{array}{c}0.3166^{\mathrm{a}} \mathrm{b} \\
(0.0283)\end{array}$ & $\begin{array}{c}0.3752 \\
(0.0489)\end{array}$ & $\begin{array}{c}0.0082 \\
(0.0022)\end{array}$ & $\begin{array}{c}0.2720^{\mathrm{b}} \\
(0.0376)\end{array}$ \\
\hline 3 & BB & $\begin{array}{c}0.6185 \\
(0.0570)\end{array}$ & $\begin{array}{c}0.2445 \\
(0.0308)\end{array}$ & $\begin{array}{c}0.3922 \\
(0.0503)\end{array}$ & $\begin{array}{c}0.0042 \\
(0.0012)\end{array}$ & $\begin{array}{c}0.2927 \\
(0.0419)\end{array}$ \\
\hline
\end{tabular}

Letters indicate differences between ++ follicular types $P<0.05$

Asterisks indicate differences between genotypes within a follicular type $P<0.05$ 
TABLE 10. Mean (s.e.m) volume, $\mu \mathrm{m}^{3}$, of oocyte structures for each follicular type and genotype

\begin{tabular}{|c|c|c|c|c|c|c|c|c|c|}
\hline $\begin{array}{c}\text { Follicular } \\
\text { Type }\end{array}$ & Genotype & SER & Golgi & Mitochondria & Vesicles & Lipid & ZP & CG & Ribosomes \\
\hline 1 & ++ & $\begin{array}{c}498^{\mathrm{a}} \\
(30)\end{array}$ & $\begin{array}{c}127^{\mathrm{a}} \\
(27)\end{array}$ & $\begin{array}{c}641^{\mathrm{a}} \\
(44)\end{array}$ & $\begin{array}{c}778^{\mathrm{a}} \\
(81)\end{array}$ & $\begin{array}{c}76^{\mathrm{a}} \\
(21)\end{array}$ & $\begin{array}{c}0^{\mathrm{a}} \\
(0)\end{array}$ & $\begin{array}{c}0.2^{\mathrm{a}} \\
(0.14)\end{array}$ & $\begin{array}{c}41^{\mathrm{a}} \\
(5)\end{array}$ \\
\hline \multirow{2}{*}{1} & $\mathrm{BB}$ & $\begin{array}{c}673^{*} \\
(26)\end{array}$ & $\begin{array}{c}109 \\
(18)\end{array}$ & $\begin{array}{c}1012^{*} \\
(70)\end{array}$ & $\begin{array}{c}645 \\
(141)\end{array}$ & $\begin{array}{c}97 \\
(33)\end{array}$ & $\begin{array}{c}34^{*} \\
(29)\end{array}$ & $\begin{array}{c}3.4 \\
(2.4)\end{array}$ & $\begin{array}{c}59 \\
(5)\end{array}$ \\
\hline 2 & ++ & $\begin{array}{c}1564^{\mathrm{b}} \\
(233)\end{array}$ & $\begin{array}{c}272^{\mathrm{a}} \\
(76)\end{array}$ & $\begin{array}{c}2963^{\mathrm{b}} \\
(429)\end{array}$ & $\begin{array}{c}1146^{\mathrm{a}} \\
(155)\end{array}$ & $\begin{array}{c}706^{\mathrm{b}} \\
(180)\end{array}$ & $\begin{array}{c}491^{\mathrm{b}} \\
(173)\end{array}$ & $\begin{array}{c}1.9^{\mathrm{a}} \\
(1.0)\end{array}$ & $\begin{array}{c}116^{\mathrm{b}} \\
(14)\end{array}$ \\
\hline 2 & $\mathrm{BB}$ & $\begin{array}{c}1115 \\
(118)\end{array}$ & $\begin{array}{c}245 \\
(61)\end{array}$ & $\begin{array}{c}2246 \\
(333)\end{array}$ & $\begin{array}{c}884 \\
(168)\end{array}$ & $\begin{array}{c}251^{*} \\
(28)\end{array}$ & $\begin{array}{c}768 \\
(336)\end{array}$ & $\begin{array}{c}11.2 \\
(4.3)\end{array}$ & $\begin{array}{c}127 \\
(10)\end{array}$ \\
\hline 3 & ++ & $\begin{array}{c}5242^{\mathrm{c}} \\
(598)\end{array}$ & $\begin{array}{c}1046^{\mathrm{b}} \\
(203)\end{array}$ & $\begin{array}{c}11301^{\mathrm{c}} \\
(1434)\end{array}$ & $\begin{array}{c}2914^{\mathrm{b}} \\
(465)\end{array}$ & $\begin{array}{c}1384^{\mathrm{b}} \\
(264)\end{array}$ & $\begin{array}{c}25997^{\mathrm{c}} \\
(4420)\end{array}$ & $\begin{array}{c}145^{\mathrm{b}} \\
(47)\end{array}$ & $\begin{array}{c}646^{\mathrm{c}} \\
(49)\end{array}$ \\
\hline 3 & $\mathrm{BB}$ & $\begin{array}{c}5621 \\
(1029)\end{array}$ & $\begin{array}{c}1491 \\
(444)\end{array}$ & $\begin{array}{c}13401 \\
(2111)\end{array}$ & $\begin{array}{c}3802 \\
(766)\end{array}$ & $\begin{array}{c}949 \\
(196)\end{array}$ & $\begin{array}{c}26880 \\
(7678)\end{array}$ & $\begin{array}{c}337 \\
(90)\end{array}$ & $\begin{array}{c}1122^{*} \\
(98)\end{array}$ \\
\hline
\end{tabular}

Letters indicate differences between ++ follicular types $P<0.05$

Asterisks indicate differences between genotypes within a follicular type $P<0.05$ 
TABLE 11. Mean (s.e.m.) surface area, $\mu m^{2}$, of oocyte membranes for each follicular type and genotype

\begin{tabular}{|c|c|c|c|c|c|c|}
\hline $\begin{array}{l}\text { Follicular } \\
\text { Type }\end{array}$ & Genotype & $\begin{array}{c}\text { Outer } \\
\text { Mitochondrial } \\
\text { Membrane }\end{array}$ & $\begin{array}{c}\text { Inner } \\
\text { Mitochondrial } \\
\text { Membrane }\end{array}$ & $\begin{array}{l}\text { Oocyte } \\
\text { Membrane }\end{array}$ & Junctions & Microvilli \\
\hline 1 & ++ & $\begin{array}{c}5187^{a} \\
(377)\end{array}$ & $\begin{array}{c}2854^{a} \\
(319)\end{array}$ & $\begin{array}{c}3520^{a} \\
(251)^{2}\end{array}$ & $\begin{array}{l}33^{a} \\
(10)\end{array}$ & $\begin{array}{c}1343^{a} \\
(171)^{2}\end{array}$ \\
\hline 1 & BB & $\begin{array}{c}8446 \text { * } \\
(535)\end{array}$ & $\begin{array}{l}4096 \\
(493)\end{array}$ & $\begin{array}{c}4882 \text { * } \\
(390)\end{array}$ & $\begin{array}{l}92 * \\
(18)\end{array}$ & $\begin{array}{l}1803 \\
(274)\end{array}$ \\
\hline 2 & ++ & $\begin{array}{c}25647^{b} \\
(3436)\end{array}$ & $\begin{array}{c}13122^{b} \\
(2012)\end{array}$ & $\begin{array}{c}104588^{b} \\
(1720)\end{array}$ & $\begin{array}{c}179^{b} \\
(37)\end{array}$ & $\begin{array}{c}5036 \text { b } \\
(968)\end{array}$ \\
\hline 2 & BB & $\begin{array}{l}19993 \\
(2387)\end{array}$ & $\begin{array}{l}9938 \\
(1617)\end{array}$ & $\begin{array}{l}8055 \\
(993)\end{array}$ & $\begin{array}{l}159 \\
(31)\end{array}$ & $\begin{array}{l}4074 \\
(834)\end{array}$ \\
\hline 3 & ++ & $\begin{array}{c}110688^{c} \\
(9582)\end{array}$ & $\begin{array}{c}52104^{c} \\
(4785)\end{array}$ & $\begin{array}{c}63329^{c} \\
(10261)\end{array}$ & $\begin{array}{c}1383^{c} \\
(418)\end{array}$ & $\begin{array}{c}45993^{c} \\
(7682)\end{array}$ \\
\hline 3 & BB & $\begin{array}{l}124042 \\
(23143)\end{array}$ & $\begin{array}{l}48306 \\
(8802)\end{array}$ & $\begin{array}{l}80150 \\
(18918)\end{array}$ & $\begin{array}{l}878 \\
(291)\end{array}$ & $\begin{array}{l}60275 \\
(15341)\end{array}$ \\
\hline
\end{tabular}

Letters indicate differences between ++ follicular types $P<0.05$

Asterisks indicate differences between genotypes within a follicular type $P<0.05$ 
TABLE 12. Percentage of follicles with ZP and cortical granules (CG) present with respect to follicular type and genotype

\begin{tabular}{|c|c|c|c|c|c|c|}
\hline \multirow{2}{*}{ Genotype } & \multicolumn{5}{|c|}{ Percentage (\%) } \\
\cline { 2 - 7 } & \multicolumn{3}{|c|}{ Zona Pellucida } & \multicolumn{3}{c|}{ Cortical Granules } \\
\cline { 2 - 7 } & Type 1 & Type 2 & Type 3 & Type 1 & Type 2 & Type 3 \\
\hline++ & $0^{\mathrm{a}}$ & $48^{\mathrm{b}}$ & $100^{\mathrm{c}}$ & $3.1^{\mathrm{a}}$ & $15^{\mathrm{b}}$ & $53^{\mathrm{c}}$ \\
\hline BB & $20^{*}$ & 56 & 100 & 8.9 & 36 & 63 \\
\hline
\end{tabular}

Letters indicate differences between ++ follicular types $P<0.05$

Asterisks indicate differences between genotypes within a follicular type $P<0.001$ 


\section{Discussion}

\subsection{Lamb and ovarian weights}

The results of this study demonstrate that lamb and ovarian weights of BB animals are lower than those of the ++ genotype. This is unlikely to be due to the greater litter size of the BB lambs as there was no correlation between litter size and birth weight or litter size and ovarian weight. The above differences between genotypes are more likely to be caused by a maternal effect of the FecB gene. In a study by Gootwine et al., 2006 [33], BB ewe lambs were found to have a lower mean birth weight than ++ ewe lambs. BB

and $\mathrm{B}+$ lambs born to BB mothers had lower birth weights than those born to $\mathrm{B}+$ and ++ ewes suggesting a possible maternal effect of the FecB gene. However, in that study, litter size was not controlled for. In the present study, there were two BB lambs (9 and 185) from twin litters and these had lower birth weights than the ++ lambs which were all from twin litters (Table 4). Lamb 185 also had a lower mean ovarian weight than the ++ lambs but unfortunately ovarian weights were not recorded for lamb 9 although the ovaries were visibly smaller.

In another study, on Booroola sheep during foetal life, Smith et al., 1993 [34] reported that at day 135 of gestation the mean body weight of BB animals (i.e. $2288 \mathrm{~g}$ ) was less than that of the ++ animals (i.e. $3653 \mathrm{~g}$ ). These weights compare closely to those obtained from the 4 week old lambs in the current study. The mean ovarian weights at days 95 and 135 of gestation were 
greater in the ++ than in the BB lambs. In a follow-up study, litter size was equalised using embryo transfer and no genotype differences in body weight at any stage of development were found. The only difference in weights between the genotypes was observed in BB foetuses which had a greater mean ovarian weight than in ++ foetuses at day 90 [35]. However, it is worth noting in this study that, the transfer of embryos into non-carrier ewes would have removed any maternal effect of the FecB gene. The mean number of germ cells in the BB ovaries was greater than in the ++ ovaries at days 90 , 100 and 135 even though the ovarian weights were the same at all stages of development except day 90 [3].

In the present study, the two BB lambs (97 and 188) with abnormal or missing reproductive tracts were from litters with two or three males present. It is possible that androgens from these males may have affected the development of the female reproductive tracts. However, in another two BB ewe lambs with normal reproductive tracts, one was born with two male siblings and the other with four. Therefore it is unlikely that androgens from the male siblings per se were the cause of the abnormalities in the reproductive tracts of lambs 97 and 188.

While not discounting a maternal effect, it seems evident that the pattern of follicular formation and development is different in BB ewes than in ++ ewes, and it is likely that any differences noted in ovarian weight in post-natal life are a continuation of this effect. 


\section{$\underline{4.2 \quad \text { Follicular types }}$}

In this study there appeared to be a genotype difference in the proportion of each follicular type observed in the LM sections with the BB animals having a lower proportion of type 1 and a greater proportion of type 2 follicles than the ++ animals (Table 5). This could indicate that more follicles have entered the growth path in the BB ovaries. Every follicle sectioned through the oocyte nucleus in all LM sections was measured. However a measure of the ovarian cortex volume was not obtained so that the total numbers of each follicular type in the ovarian cortex was not determined. Cognie et al., 1998 [36] reported a lower proportion of follicles less than $50 \mu \mathrm{m}$ (type 1/1a) and a greater proportion of follicles between 51 and $150 \mu \mathrm{m}$ (type 2 to 3) in BB ovarian sections when compared to ++. This is in agreement with the current study.

However, in studies of foetal ovaries, Smith et al., 1993, 1994 [34, 35] reported a greater number of primordial (type 1) follicles and less primary (type 2), secondary and tertiary follicles in BB compared to ++ ovaries at day 135 of foetal development. In contrast however, these authors reported a greater number of primordial follicles in ++ ovaries than in BB at days 90 and 95, so there appears to be some variation. In the Cognie study, the animals were adults, but their ages were not stated. Importantly, there is evidence that follicular populations decline with age [37]. In the current study on ewe lambs, the BB ovaries were $69 \%$ smaller by weight than in the ++ lambs, and the follicles may have been concentrated into a smaller volume of cortex 
making it easier to locate the type 2 follicles. However, this does not explain the lower proportion of type 1 follicles observed and similar numbers of follicles were measured from each genotype.

Collectively the evidence is consistent with the notion that ovarian, as well as follicular, development are influenced by genotype and age.

\section{$4.3 \quad$ Oocyte diameter}

The mean oocyte diameters in types $1,1 \mathrm{a}$ and 2 follicles of ++ ewe lambs were between 23 to $31 \%$ smaller and the type 3 diameters were $7 \%$ smaller, than those published by Lundy et al. (1999) [1] for oocytes in ovaries of wildtype ewes which were processed for LM. Glutaraldehyde fixation for EM can cause tissue to shrink between 5 to $10 \%$ and other steps in the process can cause either swelling (eg. osmium tetroxide) or shrinkage (eg. dehydration and embedding) [38]. Oocytes are very large cells and might therefore be expected to shrink more than smaller cells due to the loss of soluble components from the cytoplasm during the dehydration process. The oocytes in type 3 follicles may have been more protected by the multiple layers of granulosa cells surrounding them which could explain the reduced shrinkage at this stage of development.

It appears from this study that type 1 and 1 a follicles are formed with a larger oocyte in BB ewe lambs than in ++ but once follicular growth begins the 
oocyte volume is similar in both genotypes. Cognie et al., 1998 [36] reported that the mean oocyte diameters in BB and ++ ewes were the same in follicles less than $50 \mu \mathrm{m}$ diameter (type $1 / 1 \mathrm{a}$ ) but that the mean oocyte diameters were larger in BB than in ++ for follicles greater than $50 \mu \mathrm{m}$ diameter. However, only between 18 to 24 follicles less than $50 \mu \mathrm{m}$ and 18 to 34 follicles between 51 and $100 \mu \mathrm{m}$ were measured from each genotype compared to the current study which measured oocytes from between 247 and 324 type 1 follicles and 46 to 85 type 2 follicles. The follicles in Cognie's study were classified on the basis of follicular diameter and, according to Lundy et al., 1999 [1], those between 51 and $100 \mu \mathrm{m}$ could include type 1, 1a, 2 and 3 follicles. Wilson et al., 2001 [29] reported a greater oocyte diameter with respect to follicular volume from the late type 3 stage of development in BB ovaries but the earlier stages of development were not examined. It is possible the lack of significant genotype differences in the diameters of the type 3 oocytes from the present study was due to the limited number of oocytes measured but this seems unlikely as $19++$ and 20 BB type 3 oocytes were measured which is comparable to the 10 to 20 measured by Wilson et al., 2001 [29].

There appeared to be a weak correlation between ovarian weight and oocyte diameter in the type 1 and 2 follicles with the type 1 oocytes having a negative correlation and the type 2 oocytes a positive correlation (Fig 5). However these correlations were not statistically different. It is unlikely therefore that the genotype difference in the mean oocyte diameters in type 1 follicles was caused by the lower ovarian weight. 


\subsection{Ultrastructural changes with respect to follicular type and genotype}

\subsubsection{Comparison with other studies}

In general the ultrastructural properties of oocytes described in this study are similar to those described in early stage sheep follicles by Tassell \& Kennedy, 1980 [12], including the abundance of SER and lack of RER. Tassell \& Kennedy reported the presence of ZP in some primordial follicles. However, this observation differs from what was noted in the type 1 follicles of ++ ewe lambs in the current study, in which no ZP was found. It was however, similar to the BB follicles which appear to develop ZP earlier. In the study of Tassell \& Kennedy the breed of sheep was not described and the timing of ZP deposition may vary between breeds. These authors also reported that some primordial follicles appeared to be degenerating and had increased numbers of empty vesicles. However, in the current study, and that by Baker \& Franchi, 1972 [17] oocytes with abundant vesicles did not show any other sign of degeneration, so this may not be a good indicator of oocyte health. Unlike oocytes in primordial follicles from other species, (e.g. human and cow), the organelles in oocytes of type 1 follicles in the ewe-lambs were not co-located in a Balbiani vitelline body.

In the porcine ovary, the $\mathrm{V}_{\mathrm{v}}$ of $\mathrm{ER}$, mitochondria and lipid in oocytes of primordial follicles were, 2-, 1.6- and 5.3-fold respectively, greater than those found in the oocytes of type 1 follicles in the current study. The vesicle $V_{v}$ in the porcine ovaries was half that observed in sheep [13]. In de Bruin's study, 
2002 [6], of human follicles, the $V_{v}$ of Golgi, vesicles and lipid in oocytes from primordial and primary follicles were between 0.2 and 0.3 that of type 1 follicles in sheep, while the mitochondrial $V_{v}$ was similar. Collectively these three studies used similar methods of determining the $V_{v}$ and the values are comparable.

\subsubsection{Nucleus}

In a study by Fair et al., 1997 [39], oocyte nuclei in primordial and primary follicles of the cow contained condensed chromatin and did not stain positively for ${ }^{3} \mathrm{H}$-uridine indicating these nuclei were not actively transcribing RNA until the secondary (late type 2) and tertiary (type 3) stages of development. This differs from the observations made in the present study where very little or no condensed chromatin was present in oocyte nuclei of follicles at the type 1 to 3 stages of development. This suggests that sheep oocytes are undergoing more active gene transcription from an earlier stage of development than in some other species.

\subsubsection{Smooth endoplasmic reticulum}

SER is a network of membranes involved in lipid absorption and metabolism, glycogen metabolism and membrane formation and recycling. In the oocyte the SER would most likely be involved in synthesising membrane for the oolemma and organelles as the oocyte volume increases. Steroid synthesis is not likely to be occurring as no steroidogenic enzymes are expressed in oocytes of follicles at the type 1 to 5 stages of development [40]. In the present study, the $V_{v}$ of the SER in the oocytes decreased as the follicles 
changed from the type 1 to the type 3 stage of development which meant that the SER volume did not increase as much as the oocyte volume. The SER volume in oocytes of type 1 follicles from BB lambs was greater than that of the ++ which suggests that these early BB oocytes have the ability to synthesize more membrane and metabolise more lipid.

\subsubsection{Golgi}

Golgi complexes are associated with processing and packaging macromolecules that are synthesised by the cell, such as proteins and lipids. They are important in concentrating secretory products such as the cortical granules and ZP and they reach their maximum development when these latter structures are produced [41]. In the current study, the $V_{v}$ of Golgi decreased slightly in the oocytes from the type 1 to 3 stages of follicular development and therefore the Golgi volume increased less than the increase observed for oocyte volume. It is possible that ovine oocytes already possess the necessary density of Golgi complexes for protein and lipid trafficking, and that this requirement does not change greatly during early oocyte development.

\subsubsection{Mitochondria}

Mitochondria are involved mainly in the production of ATP as an energy source for cellular functions and they contain DNA-encoding proteins important for mitochondrial function. Human primordial germ cells form with only approximately 10 mitochondria which increase in number to several hundreds of thousands in the mature oocyte. The majority of the 
mitochondria observed in this study were round with arched cristae, and this form of mitochondria has been described as being scarcely differentiated with low metabolic activity $[42,43]$. This undeveloped state may limit the oxidative phosphorylation capacity of the organelle and reduce the potential for generating reactive oxidative species that could inhibit mitochondrial function or initiate apoptosis [43]. The energy demands of the oocyte may either be minimal or met by ATP supplied by glycolysis or imported from the surrounding granulosa cells. Dumollard et al., 2007 [44] states that the mitochondrial and protein components in the egg have a low rate of turnover and that the maternal component of enzymes required for oxidative phosphorylation is sufficient to support early development. Mitochondria in oocytes of other species (e.g. cattle) [11], have been described as containing dense matrix granules but these were not observed in the mitochondria in this study.

The mitochondrial $V_{v}$, outer and inner mitochondrial $S_{v}$ and number per area sampled all increased in the oocyte between 1.4- and 1.5-fold when the follicles grew from the type 1 to type 2 stage of development. This implies that mitochondrial number must increase to supply an increased energy demand when oocyte growth begins. In oocytes of type 1 follicles from BB ovaries the mitochondrial $V_{v}$, outer mitochondrial membrane $S_{v}$ and number of mitochondria per area of oocyte sampled were all 1.2- to 1.3-fold greater than the ++ values. The mitochondrial volume and outer mitochondrial membrane surface area were therefore also greater. This suggests that the oocytes of BB lambs are formed with more mitochondria than ++ lambs 
which could increase their metabolic rate and allow them to grow more readily from the type 1 to type 2 stage of follicular development.

\subsubsection{Mitochondria and SER association}

Most of the mitochondria in the oocytes of this study were closely associated with SER. This close proximity between the two organelles allows for the efficient transmission of cytosolic $\mathrm{Ca}^{2+}$ signals into the mitochondria to activate mitochondrial metabolism and increase ATP supply to the $\mathrm{Ca}^{2+}$ pumps in the ER $[44,45]$. Because of the long life span of mitochondria in oocytes it is important to protect them from damaging reactive oxygen species. By maintaining a low level of oxidative phosphorylation that can be stimulated by an increase in ATP demand, the oocyte can reduce the amount of mitochondrial oxidative stress it is exposed to [44].

\subsubsection{Vesicles}

The vesicles in this study, also referred to as vacuoles in other papers, varied in shape and size but little is known of their origin. Some may have originated from enlarged, degenerated mitochondria [41]. Although some vesicles observed in the sheep oocytes contained granular material the majority were electron translucent and if they had originally contained nutritional reserves these may have been removed during tissue processing. Falconnier \& Kress, 1992 [46] showed that by using potassium ferrocyanide or cetylpyridium chloride during fixation to precipitate glycogen and glycoproteins, some vesicle content was preserved in the oocytes of the grey short-tailed opossum. 
The $V_{v}$ of vesicles in oocytes of ++ lambs decreased from the type 1 to the type 3 stage of follicular development. This meant that the vesicle volume only increased 2.5-fold between the type 2 and 3 stage of development which is less than the 5.5-fold increase in oocyte volume. If the vesicles contained maternal metabolites these may have been depleted during early follicular growth which could explain the reduction in the vesicle $V_{v}$. The $V_{v}$ of vesicles in the oocytes of BB lambs was less than that of the ++ animals in the type 1 follicles. However, there was no significant genotype difference in vesicle volume due to the BB oocytes having a greater volume at this stage of development. The lower density of vesicles in the oocytes of type 1 follicles from BB lambs could indicate that these oocytes have already begun to deplete their nutritional reserves. In the cow, vesicle number appeared to increase with follicular development [11], but this probably occurred during the later antral stages of development.

\subsubsection{Lipid}

The amount of lipid droplets in the oocytes varied greatly and the droplets were often surrounded by SER. These droplets could be a source of lipid for energy metabolism and membrane synthesis and the close association with SER supports this. Occasionally mitochondria were seen to be connecting with the SER surrounding a lipid droplet, and electron-dense material was observed at the interface of these three organelles (Fig 9A). Similar structures were also observed in bovine oocytes but it is unclear what the function of these clusters of organelles might be [11]. 
In ++ animals, the $V_{v}$ of lipid increased 9-fold in oocytes from the type 1 to type 2 stages of follicular development, which was much greater than the 3fold increase in oocyte volume during this stage of development. The $V_{v}$ of lipid then decreased from the type 2 to 3 stages of follicular development. It is unclear what the source of this lipid is but it may be essential metabolite or precursor for membrane synthesis and energy during the initiation of follicular growth. Oocytes from type 2 follicles of BB lambs had a significantly lower volume of lipid than the ++ genotype. This could indicate that these oocytes have already begun to utilise the increased store of lipid at this stage of follicular development.

\subsubsection{Ribosomes}

Cytoplasmic ribosomes synthesise protein that remains in the cell, such as mitochondrial enzymes and cytoskeletal proteins, whereas ribosomes associated with ER produce protein that becomes packaged by the Golgi and exported from the cell. The lack of RER and small amount of Golgi and free ribosomes in the early stage oocytes of this study suggests that during early follicular development the oocyte may be synthesising very little protein for utilisation within the cell. These oocytes may rely on proteins manufactured during foetal development. RER was observed in oocytes of type 1 follicles from the cow and pig but not in the mouse and human, indicating there are species differences in the patterns of protein synthesis $[6,8,11,13]$. 
In ++ animals there was no change in the $V_{v}$ of ribosomes between the oocytes of types 1,2 and 3 follicles and the volume increase of the ribosomes was therefore equivalent to the increase in the oocyte volume. However, the oocytes of type 3 follicles from BB lambs had a greater $V_{v}$ and volume of ribosomes than the ++ lambs. This increased volume of ribosomes would enable oocytes from BB lambs to synthesise more protein for the production of enzymes, growth factors and structures within the cell and for signalling to the surrounding granulosa cells.

\subsubsection{Zona pellucida}

The $\mathrm{ZP}$ is an extracellular matrix surrounding the oocyte and depending on the species, consists of 3 or 4 glycoproteins. It plays an important role during fertilisation by providing a binding-site for sperm and activating the acrosome reaction which allows the sperm to penetrate the oocyte. In the mouse, ZP glycoproteins are synthesised and secreted by growing oocytes but not by granulosa cells [47]. This is in contrast to the cat, in which ZP is produced exclusively in the granulosa cells, and the rabbit in which ZP glycoproteins are produced by both the oocyte and granulosa cells $[48,49]$. The lack of RER in the oocytes from the current study suggests that the oocytes may not have the machinery to synthesise and secrete large amounts of ZP glycoproteins, and that perhaps, for sheep, this occurs mainly in the granulosa cells. However, mouse oocytes which were shown to synthesise ZP did not contain RER either [8]. Further research is needed to determine the site/s of ZP synthesis in sheep follicles. 
Small amounts of ZP deposits are more visible by EM than by LM and this technique allows the initiation of ZP accumulation to be determined. ZP deposition occurs earlier in the follicles of BB lambs with $20 \%$ of the type 1 follicles having ZP present while ZP was not observed in any type 1 follicles from ++ lambs. This suggests that follicles from BB animals have the ability to synthesise ZP and/or are somehow stimulated to begin ZP deposition at an earlier stage of development. Oocytes from BB animals ovulate at an earlier stage of development with less granulosa cells than the ++ oocytes but probably require the same amount of ZP for successful fertilisation to occur. By beginning ZP deposition earlier, oocytes of BB animals would be able to accumulate the volume of ZP required for fertilisation sooner. The $V_{v}$ of ZP increases during growth from a type 1 to a type 3 stage follicle with the volume increasing 53 -fold between the type 2 and 3 stages in the ++ ovaries. There were no significant genotype differences in the volume of ZP in ovarian follicles of BB and ++ lambs apart from at the type 1 stage of follicular development.

\subsubsection{Cortical granules}

Cortical granules are small, spherical, membrane-bound organelles containing glycoproteins and trypsin-like protease whose formation is closely associated with the SER in bovine and porcine oocytes, rather than with RER and Golgi as in other species [41]. At fertilisation the cortical granules are exocytosed to release their enzymes which alter the ZP structure to prevent fertilisation by multiple sperm. 
In ++ ovaries, the percentage of oocytes containing cortical granules increased from $3 \%$ of the type 1 follicles to $53 \%$ of the type 3 follicles. The cortical granule volume increased 76 -fold between the type 2 and 3 stages of follicular development. This would allow a steady accumulation of cortical granules to occur during oocyte growth to ensure there were enough enzymes present for ZP alteration during the fertilisation process. Cortical granule percentage, $V_{v}$ and volume each appeared to be greater in the oocytes of follicles from BB lambs at all stages of development but these were not statistically significant due to the small amount present and the large variation. Again, an increase in the amount of cortical granules present at earlier stages of development would allow the oocytes of BB lambs to mature earlier than the ++ lambs.

\subsubsection{Junctions}

The junctions observed between the oocytes and granulosa cells in this study were mainly of the zonula adherens type: these provide adhesion between the cells and prevent separation. In type 1 follicles of the human and type 2 follicles of the cow, gap junctions were observed between the oocyte and granulosa cells [11, 50]. In contrast, gap junctions were not observed between the oocyte and granulosa cells in equivalent stage follicles of the present study. Connexins are expressed in the sheep oocyte from the primordial stage of follicular development (K McNatty, unpublished data), but these may not be incorporated into functional gap junctions until a later stage. 
The surface area of the zonula adherens junctions between oocytes and granulosa cells increased from the type 1 to the type 3 stages of follicular development. The fold-increase in the ++ follicles was slightly greater than the increase in oocyte volume. The type 1 follicles of the BB lambs had a significantly greater $S_{v}$ and surface area than the ++ but the changes in the surface area after this were equivalent to the changes in oocyte volume. It appears that more junctions are formed earlier in the BB follicle but that the ++ follicles catch up at subsequent stages of development.

\subsubsection{Microvilli}

Microvilli increase the surface area of the oocyte through which substances can be secreted or absorbed. In the oocytes of ++ lambs, the microvilli $S_{v}$ increased between the type 2 and 3 stages of follicular development and the

surface area increased about double that of the oocyte volume increase. There did not appear to be any genotype differences in the surface area of oocyte microvilli.

\subsection{ALK6 mutation and oocyte ultrastructure}

ALK6 mRNA is expressed in developing oogonia during foetal development ( $\mathrm{J}$ Juengel, unpublished data) therefore the effects of the ALK6 mutation on follicular formation and development could occur very early. The increased oocyte volume and differences in oocyte ultrastructure observed in the type 1 follicles of the BB lambs in this study are unlikely to be caused by BMP15 as 
this is not present until the type 2 stage of follicular development in sheep [18]. BMP2, 4, 6 and 7 are also ligands for ALK6 and therefore could potentially affect follicular formation and development in the foetal ovaries of BB animals. However, Juengel et al., 2006 [51] reported that in sheep ovaries BMP2 mRNA was only expressed in atretic follicles at the type 5 stage of development so it is unlikely to have an effect on early follicular development. In the same study, BMP4 mRNA was observed in the surface epithelium and blood vessels of the ovaries of lamb and adult ewes and in the tubules of sheep foetal kidney so could potentially affect follicular formation and development. In contrast, BMP6 mRNA was expressed in oocytes of healthy follicles from the type 1 stage of development in sheep and is likely be a ligand involved in ALK6 mediated changes to the structure of oocytes of type 1 follicles from BB lambs. BMP7 mRNA expression was not observed in oocytes but was present in rete tubules. BMP7 has been shown to activate primordial follicles in the rat despite not being expressed in rat primordial follicles [52]. Further studies are required to determine which ligands for ALK6 are present during foetal development in sheep and which of these could affect follicular formation and development. At present it seems that BMP6 is the most likely candidate.

Once follicular growth has been initiated in the sheep, the granulosa cell number doubles and the oocyte diameter increases between 1.2- and 1.4fold at each stage of development [1]. The increased volume or surface area of SER, mitochondria and junctions with the granulosa cells in the oocytes of type 1 follicles of BB lambs may allow these oocytes to begin to grow without 
waiting for an associated increase in granulosa cell number to supply metabolites.

\subsection{Summary}

Significant changes in the volumes of organelles and structures in oocytes occur between the type 1 and the type 3 stages of follicular development. In ++ lambs the volumes and surface areas of SER, Golgi, mitochondria, vesicles, lipid, ZP, cortical granules, ribosomes, junctions between the oocyte and granulosa cells and microvilli all increase during these early stages of follicular growth. The volume density or surface density of the SER, Golgi, vesicles, ribosomes and junctions remain either constant or reduce during early follicular development. However, mitochondria, lipid, ZP, cortical granules and microvilli all exhibit significant increases in their $\mathrm{V}_{\mathrm{v}}$ or $\mathrm{S}_{\mathrm{v}}$. This implies that these organelles and structures are involved in important metabolic changes that must occur in the oocyte for follicular growth to progress and/or for oocyte maturation to occur.

BB lambs have significant differences in the ultrastructural composition of oocytes in the type 1 follicles when compared to ++ lambs. Oocytes in the type 1 follicles are formed larger and with a greater volume and surface area of SER, mitochondria, ZP and zonula adherens junctions. The oocytes in type 1 follicles of BB lambs appear to be formed with the sub-cellular machinery required for them to grow to the type 2 stage of follicular 
development while oocytes in the ++ ovaries appear to require an increase in the density of organelles and structures before follicular growth can occur.

In conclusion, the original hypothesis that differences in the ultrastructure of oocytes in follicles from BB lamb ovaries would be observed from the type 2 stage of follicular development onwards, must be rejected. Differences were observed in the type 1 follicles and are therefore unlikely to be caused by the initiation of expression of BMP15 in oocytes and ALK6 in granulosa cells which does not occur until the type 2 stage of follicular development. However, the volume of organelles involved in energy production and membrane synthesis did increase earlier in oocytes from BB lamb ovaries compared to ++ as was expected. Further studies on foetal ovaries are required to determine exactly when these differences in oocyte structure occur, which ligands are involved and how the ALK6 mutation alters the effects of these ligands. 


\section{References}

1. Lundy T, Smith P, O'Connell A, Hudson NL, McNatty KP. Populations of granulosa cells in small follicles of the sheep ovary. J Reprod Fertil 1999; 115: 251-262.

2. Picton HM. Activation of follicle development: the primordial follicle. Theriogenology 2001; 55: 1193-1210.

3. Sawyer HR, Smith P, Heath DA, Juengel JL, Wakefield SJ, McNatty KP. Formation of ovarian follicles during fetal development in sheep. Biol Reprod 2002; 66: 11341150.

4. Sathananthan AH. Ultrastructure of the human egg. Hum Cell 1997; 10: 21-38.

5. Hertig AT, Adams EC. Studies on the human oocyte and its follicle. I. Ultrastructural and histochemical observations on the primordial follicle stage. J Cell Biol 1967; 34: 647-675.

6. de Bruin JP, Dorland M, Spek ER, Posthuma G, van Haaften M, Looman CW, te Velde ER. Ultrastructure of the resting ovarian follicle pool in healthy young women. Biol Reprod 2002; 66: 1151-1160.

7. Zamboni L. Fine morphology of the follicle wall and follicle cell-oocyte association. Biol Reprod 1974; 10: 125-149.

8. Wassarman PM, Josefowicz WJ. Oocyte development in the mouse: an ultrastructural comparison of oocytes isolated at various stages of growth and meiotic competence. J Morphol 1978; 156: 209-235.

9. Dvorak M. Ultrastructure and quantitative analysis of mouse and human oocytes. Prog Clin Biol Res 1989; 296: 273-280.

10. Devine PJ, Payne CM, McCuskey MK, Hoyer PB. Ultrastructural evaluation of oocytes during atresia in rat ovarian follicles. Biol Reprod 2000; 63: 1245-1252.

11. Fair T, Hulshof SC, Hyttel P, Greve T, Boland M. Oocyte ultrastructure in bovine primordial to early tertiary follicles. Anat Embryol (Berl) 1997; 195: 327-336.

12. Tassell R, Kennedy JP. Early follicular development and atretic changes in the ovary of the lamb-- fine structure and histochemistry. Aust J Biol Sci 1980; 33: 675-687.

13. Bielanska-Osuchowska Z. Oogenesis in pig ovaries during the prenatal period: ultrastructure and morphometry. Reprod Biol 2006; 6: 161-193.

14. Frankenberg S, Selwood L. Ultrastructure of oogenesis in the brushtail possum. Mol Reprod Dev 2001; 58: 297-306.

15. Matos MH, Andrade ER, Lucci CM, Bao SN, Silva JR, Santos RR, Ferreira MA, Costa SH, Celestino JJ, Figueiredo JR. Morphological and ultrastructural analysis of sheep primordial follicles preserved in $0.9 \%$ saline solution and TCM 199. Theriogenology 2004; 62: 65-80. 
16. Mhawi AJ, Kanka J, Motlik J. Follicle and oocyte growth in early postnatal calves: cytochemical, autoradiographical and electron microscopical studies. Reprod Nutr Dev 1991; 31: 115-126.

17. Baker TG, Franchi LL. Electron microscope studies of radiation-induced degeneration in oocytes of the sexually mature rhesus monkey. Z Zellforsch Mikrosk Anat 1972; 133: 435-454.

18. Juengel JL, McNatty KP. The role of proteins of the transforming growth factor-\{beta\} superfamily in the intraovarian regulation of follicular development. Hum Reprod Update 2005.

19. Elvin J, Yan, C. and Matzuk, M.M. Oocyte-expressed TGF-beta superfamily members in female fertility. Mol Cell Endocrinol 2000; 159: 1-5.

20. Eppig JJ. Oocyte control of ovarian follicular development and function in mammals. Reproduction 2001; 122: 829-838.

21. McNatty KP, Smith P, Moore LG, Reader K, Lun S, Hanrahan JP, Groome NP, Laitinen M, Ritvos $\mathrm{O}$, Juengel JL. Oocyte-expressed genes affecting ovulation rate. Mol Cell Endocrinol 2005; 234: 57-66.

22. Carabatsos MJ, Elvin J, Matzuk MM, Albertini DF. Characterization of oocyte and follicle development in growth differentiation factor-9-deficient mice. Dev Biol 1998; 204: 373-384.

23. Abel MH, Wootton AN, Wilkins V, Huhtaniemi I, Knight PG, Charlton HM. The effect of a null mutation in the follicle-stimulating hormone receptor gene on mouse reproduction. Endocrinology 2000; 141: 1795-1803.

24. McNatty KP, Heath DA, Lundy T, Fidler AE, Quirke L, O'Connell A, Smith P, Groome N, Tisdall DJ. Control of early ovarian follicular development. J Reprod Fertil Suppl 1999; 54: 3-16.

25. Shimasaki S, Moore RK, Otsuka F, Erickson GF. The bone morphogenetic protein system in mammalian reproduction. Endocr Rev 2004; 25: 72-101.

26. Moore RK, Otsuka F, Shimasaki S. Molecular basis of bone morphogenetic protein15 signaling in granulosa cells. J Biol Chem 2003; 278: 304-310.

27. McNatty KP, Juengel JL, Wilson T, Galloway SM, Davis GH. Genetic mutations influencing ovulation rate in sheep. Reprod Fertil Dev 2001; 13: 549-555.

28. Albertini DF, Combelles CM, Benecchi E, Carabatsos MJ. Cellular basis for paracrine regulation of ovarian follicle development. Reproduction 2001; 121: 647653.

29. Wilson $T$, Wu XY, Juengel JL, Ross IK, Lumsden JM, Lord EA, Dodds KG, Walling GA, McEwan JC, O'Connell AR, McNatty KP, Montgomery GW. Highly prolific Booroola sheep have a mutation in the intracellular kinase domain of bone morphogenetic protein IB receptor (ALK-6) that is expressed in both oocytes and granulosa cells. Biol Reprod 2001; 64: 1225-1235.

30. McNatty KP, Galloway SM, Wilson T, Smith P, Hudson NL, O'Connell A, Bibby AH, Heath DA, Davis GH, Hanrahan JP, Juengel JL. Physiological effects of major genes affecting ovulation rate in sheep. Genet Sel Evol 2005; 37 Suppl 1: S25-38. 
31. Yi SE, LaPolt PS, Yoon BS, Chen JY, Lu JK, Lyons KM. The type I BMP receptor BmprlB is essential for female reproductive function. Proc Natl Acad Sci U S A 2001; 98: 7994-7999.

32. Wiliams M. Quantitative Methods in Biology. Amsterdam: Elsevier/North-Holland Biomedical Press; 1977.

33. Gootwine E, Rozov A, Bor A, Reicher S. Carrying the FecB (Booroola) mutation is associated with lower birth weight and slower post-weaning growth rate for lambs, as well as a lighter mature bodyweight for ewes. Reprod Fertil Dev 2006; 18: 433437.

34. Smith P, Hudson NL, Shaw L, Heath DA, Condell L, Phillips DJ, McNatty KP. Effects of the Booroola gene $(\mathrm{FecB})$ on body weight, ovarian development and hormone concentrations during fetal life. J Reprod Fertil 1993; 98: 41-54.

35. Smith P, Braw-Tal R, Corrigan K, Hudson NL, Heath DA, McNatty KP. Ontogeny of ovarian follicle development in Booroola sheep fetuses that are homozygous carriers or non-carriers of the FecB gene. J Reprod Fertil 1994; 100: 485-490.

36. Cognie $\mathrm{Y}$, Benoit F, Poulin N, Khatir H, Driancourt MA. Effect of follicle size and of the FecB Booroola gene on oocyte function in sheep. J Reprod Fertil 1998; 112: 379-386.

37. Gougeon A, Ecochard R, Thalabard JC. Age-related changes of the population of human ovarian follicles: increase in the disappearance rate of non-growing and early-growing follicles in aging women. Biol Reprod 1994; 50: 653-663.

38. Hayat MA. Fixation for Electron Microscopy. New York: Academic Press; 1981.

39. Fair T, Hulshof SC, Hyttel P, Greve T, Boland M. Nucleus ultrastructure and transcriptional activity of bovine oocytes in preantral and early antral follicles. Mol Reprod Dev 1997; 46: 208-215.

40. Logan KA, Juengel JL, McNatty KP. Onset of steroidogenic enzyme gene expression during ovarian follicular development in sheep. Biol Reprod 2002; 66: 906-916.

41. Ullmann SL, Butcher L. Mammalian oocyte organelles with special reference to pleomorphic mitochondria and vacuole formation in marsupials. Reprod Fertil Dev 1996; 8: 491-508.

42. Motta PM, Nottola SA, Makabe S, Heyn R. Mitochondrial morphology in human fetal and adult female germ cells. Hum Reprod 2000; 15 Suppl 2: 129-147.

43. Van Blerkom J. Mitochondria in human oogenesis and preimplantation embryogenesis: engines of metabolism, ionic regulation and developmental competence. Reproduction 2004; 128: 269-280.

44. Dumollard R, Duchen M, Carroll J. The role of mitochondrial function in the oocyte and embryo. Curr Top Dev Biol 2007; 77: 21-49.

45. Rizzuto R, Bernardi P, Pozzan T. Mitochondria as all-round players of the calcium game. J Physiol 2000; 529 Pt 1: 37-47. 
46. Falconnier C, Kress A. Ultrastructural aspects of oocyte growth in the marsupial Monodelphis domestica (grey short-tailed opossum). J Anat 1992; 181 ( Pt 3): 481498.

47. Familliari G, Relucenti, M., Heyn, R., Micara, G. and Correr, S. Three-Dimensional Structure of the Zona Pellucida at Ovulation. Microscopy Research and Technique 2006; 69: 415-426.

48. Jewgenow K, Rudolph M. Timing and location of zona pellucida synthesis during oogenesis in domestic cats--an ultrastructural immunohistological investigation. J Reprod Fertil Suppl 2001; 57: 23-29.

49. Dunbar BS, Avery S, Lee V, Prasad S, Schwahn D, Schwoebel E, Skinner S, Wilkins B. The mammalian zona pellucida: its biochemistry, immunochemistry, molecular biology, and developmental expression. Reprod Fertil Dev 1994; 6: 331-347.

50. Motta PM, Makabe S, Naguro T, Correr S. Oocyte follicle cells association during development of human ovarian follicle. A study by high resolution scanning and transmission electron microscopy. Arch Histol Cytol 1994; 57: 369-394.

51. Juengel JL, Reader KL, Bibby AH, Lun S, Ross I, Haydon LJ, McNatty KP. The role of bone morphogenetic proteins 2, 4, 6 and 7 during ovarian follicular development in sheep: contrast to rat. Reproduction 2006; 131: 501-513.

52. Lee WS, Otsuka F, Moore RK, Shimasaki S. Effect of bone morphogenetic protein-7 on folliculogenesis and ovulation in the rat. Biol Reprod 2001; 65: 994-999. 


\section{Appendices}

\section{Appendix 1-Ethical Approval}

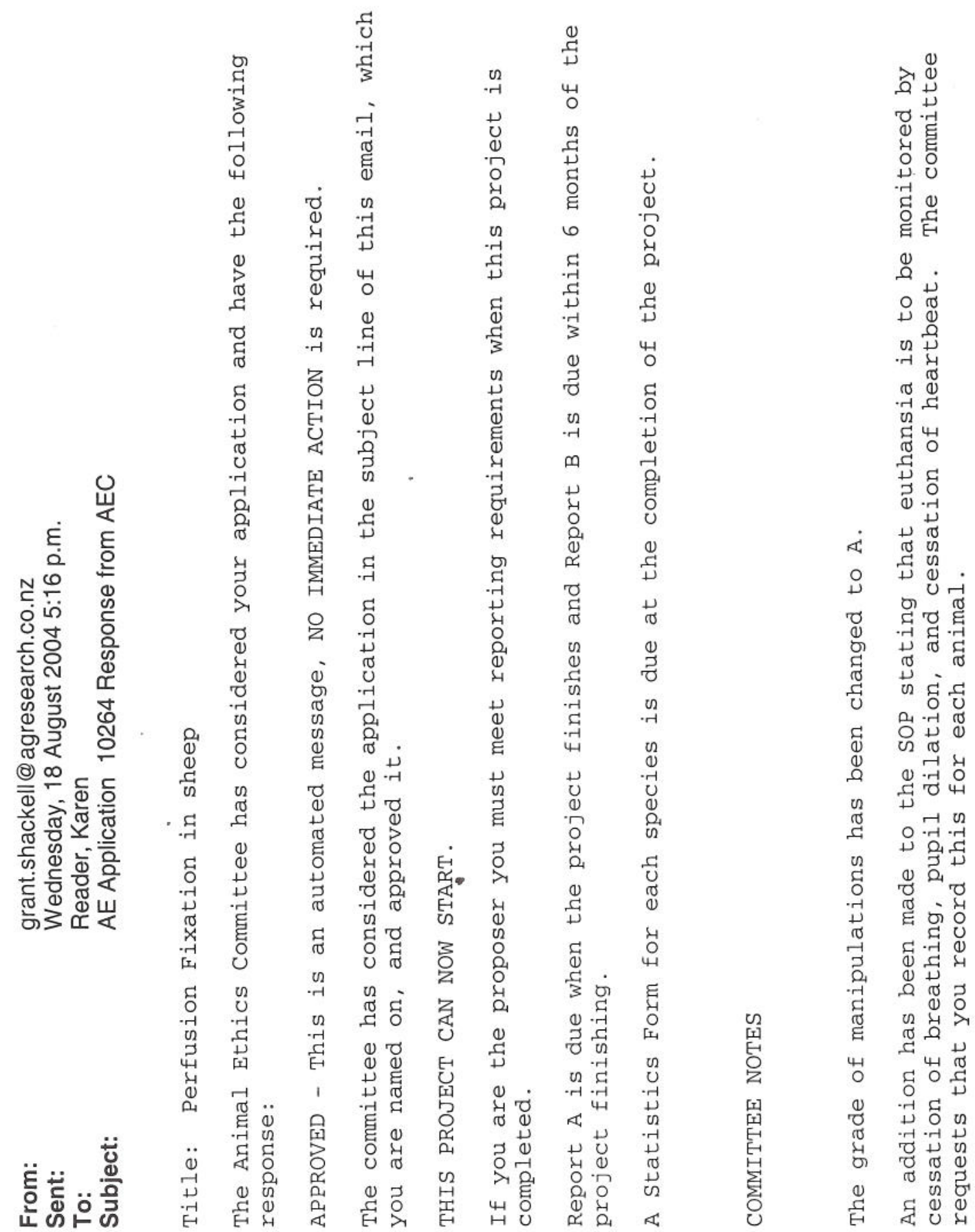




\section{Appendix 2 - Solution compositions}

All chemicals were sourced from ProSciTech, Queensland, Australia unless otherwise stated.

$\underline{0.85 \% \text { Saline }}$

$8.5 \mathrm{~g}$ Sodium chloride (BDH Chemicals, Poole, England) in $1 \mathrm{~L}$ distilled $\mathrm{H}_{2} \mathrm{O}$

Heparinised saline

$2 \mathrm{ml}$ Multiparin $5000 \mathrm{IU} / \mathrm{ml}$ heparin sodium (CP Pharmaceuticals Ltd, Wrexham, UK) in $1 \mathrm{~L}$ saline

0.1 M Sodium cacodylate buffer ( $\mathrm{NaCac}) \mathrm{pH} 7.4$

$21.4 \mathrm{~g} \mathrm{NaCac}$ in $1 \mathrm{~L}$ distilled $\mathrm{H}_{2} \mathrm{O}$

Primary fixative (4\% glutaraldehyde in $0.1 \mathrm{M} \mathrm{NaCac}$ buffer) $\mathrm{pH} 7.4$ $42.8 \mathrm{~g} \mathrm{NaCac}$ and $320 \mathrm{ml} 25 \%$ glutaraldehyde in $2 \mathrm{~L}$ distilled $\mathrm{H}_{2} \mathrm{O}$

$1 \%$ Osmium tetroxide in $0.1 \mathrm{M} \mathrm{NaCac}$ buffer

$1 \mathrm{~g}$ Osmium tetroxide in $100 \mathrm{ml} 0.1 \mathrm{M} \mathrm{NaCac}$ buffer

$\underline{2 \% \text { Uranyl acetate }}$

$4 \mathrm{~g}$ Uranyl acetate in $200 \mathrm{ml}$ distilled $\mathrm{H}_{2} \mathrm{O}$

\section{Procure 812 epoxy resin}

Pre-mix A: $40 \mathrm{ml}$ Procure 812

$64 \mathrm{ml}$ Dodecenyl succinic anhydride (DDSA) epoxy hardener

Pre-mix B: $64 \mathrm{ml}$ Procure 812

$56 \mathrm{ml}$ Methyl-5-norbornene-2,3-dicarboxylic anhydride (NMA) epoxy hardener 
Resin: $\quad 28 \mathrm{ml}$ Pre-mix A

$28 \mathrm{ml} \mathrm{Pre-mix} \mathrm{B}$

$1.6 \mathrm{ml}$ Benzyldimethylamine (BDMA) accelerator

- Mix thoroughly

$10 \mathrm{~N}$ Sodium hydroxide $(\mathrm{NaOH})$

$3.9 \mathrm{~g} \mathrm{NaOH}$ pellets (BDH Chemicals, Poole, England) in $10 \mathrm{ml}$ milliQ $\mathrm{H}_{2} \mathrm{O}$

Uranyl acetate stain

$0.1 \mathrm{~g}$ Uranyl acetate in $2 \mathrm{ml} 50 \%(\mathrm{v} / \mathrm{v})$ ethanol

- Prepare immediately before use

- Mix solution well

- Filter through $0.2 \mu \mathrm{m}$ syringe filter immediately before staining

\section{Lead citrate stain}

$1.33 \mathrm{~g}$ Lead nitrate and $1.76 \mathrm{~g}$ trisodium citrate (BDH Chemicals, Poole, England) in $30 \mathrm{ml}$ milliQ $\mathrm{H}_{2} \mathrm{O}$ boiled for $10 \mathrm{~min}$ to remove $\mathrm{CO}_{2}$ and cooled

- Shake vigorously for $1 \mathrm{~min}$ then occasionally for $30 \mathrm{~min}$

- Add $8 \mathrm{ml} 1 \mathrm{~N} \mathrm{NaOH}$ to clear solution

- Make up to $50 \mathrm{ml}$ with boiled, cooled milliQ water

- Filter through $0.2 \mu \mathrm{m}$ syringe filter immediately before staining

\section{Richardson's stain}

$1 \%$ disodium tetraborate solution

$1 \mathrm{~g}$ disodium tetraborate (BDH Chemicals, Poole, England) in $100 \mathrm{ml}$ distilled $\mathrm{H}_{2} \mathrm{O}$

\section{$1 \%$ Methylene blue}

$0.5 \mathrm{~g}$ Methylene blue (BDH Chemicals, Poole, England) in $50 \mathrm{ml} 1 \%$ disodium tetraborate solution 


\section{$1 \%$ Azur II}

$0.5 \mathrm{~g}$ Azur II (BDH Chemicals, Poole, England) in $50 \mathrm{ml} 1 \%$ disodium tetraborate solution

- Mix $50 \mathrm{ml}$ of $1 \%$ Methylene blue and $50 \mathrm{ml} 1 \%$ Azur II

- Store in a light excluded bottle

- Filter through $0.2 \mu \mathrm{m}$ syringe filter immediately before staining 


\section{Appendix 3 - Mean oocyte diameter for each animal with respect to}

follicular type and genotype

Type 1 oocyte diameters (Oo Diam) ( $n=$ number of follicles measured)

\begin{tabular}{|c|c|c|c|c|c|c|}
\hline Genotype & $\begin{array}{c}\text { Lamb } \\
\text { No }\end{array}$ & $\mathrm{n}$ & Oo Diam & SE Mean & Minimum & Maximum \\
\hline++ & 305 & 36 & 27.28 & 0.76 & 20.24 & 38.62 \\
\hline++ & 307 & 60 & 27.91 & 0.45 & 20.48 & 39.80 \\
\hline++ & 329 & 42 & 27.46 & 0.67 & 20.01 & 36.11 \\
\hline++ & 358 & 117 & 27.10 & 0.31 & 20.18 & 38.32 \\
\hline++ & 406 & 29 & 25.80 & 0.44 & 22.65 & 31.16 \\
\hline++ & 410 & 40 & 26.78 & 0.74 & 19.85 & 41.91 \\
\hline BB & 9 & 15 & 31.43 & 1.06 & 26.71 & 41.62 \\
\hline BB & 11 & 68 & 28.50 & 0.44 & 22.59 & 42.01 \\
\hline BB & 13 & 62 & 28.40 & 0.35 & 23.57 & 36.62 \\
\hline BB & 185 & 39 & 30.24 & 0.71 & 22.30 & 41.49 \\
\hline BB & 190 & 63 & 30.22 & 0.47 & 22.63 & 38.46 \\
\hline
\end{tabular}

Type 2 oocyte diameters (Oo Diam) ( $\mathrm{n}=$ number of follicles measured)

\begin{tabular}{|c|c|c|c|c|c|c|}
\hline Genotype & $\begin{array}{c}\text { Lamb } \\
\text { No }\end{array}$ & $\mathrm{n}$ & Oo Diam & SE Mean & Minimum & Maximum \\
\hline++ & 305 & 5 & 36.73 & 2.95 & 31.71 & 48.01 \\
\hline++ & 307 & 4 & 39.35 & 1.53 & 34.99 & 42.06 \\
\hline++ & 329 & 6 & 48.79 & 2.74 & 41.80 & 60.23 \\
\hline++ & 358 & 9 & 39.32 & 2.29 & 31.11 & 48.49 \\
\hline++ & 406 & 10 & 38.65 & 3.09 & 27.23 & 58.32 \\
\hline++ & 410 & 12 & 38.41 & 2.01 & 27.71 & 47.30 \\
\hline BB & 9 & 15 & 40.28 & 2.03 & 25.19 & 54.29 \\
\hline BB & 11 & 10 & 34.40 & 1.28 & 29.83 & 44.91 \\
\hline BB & 13 & 10 & 36.27 & 1.70 & 29.46 & 45.30 \\
\hline BB & 185 & 29 & 38.46 & 1.32 & 29.90 & 62.43 \\
\hline BB & 190 & 21 & 34.68 & 1.28 & 22.54 & 53.14 \\
\hline
\end{tabular}


Type 3 oocyte diameters (Oo Diam) ( $n=$ number of follicles measured)

\begin{tabular}{|c|c|c|c|c|c|c|}
\hline Genotype & $\begin{array}{c}\text { Lamb } \\
\text { No }\end{array}$ & $\mathrm{n}$ & Oo Diam & SE Mean & Minimum & Maximum \\
\hline++ & 305 & 2 & 71.31 & 8.17 & 63.14 & 79.49 \\
\hline++ & 307 & 3 & 70.91 & 9.18 & 56.62 & 88.03 \\
\hline++ & 329 & 5 & 63.14 & 8.52 & 37.87 & 84.96 \\
\hline++ & 358 & 3 & 68.92 & 2.03 & 65.36 & 72.40 \\
\hline++ & 406 & 2 & 65.50 & 1.96 & 63.53 & 67.46 \\
\hline++ & 410 & 4 & 68.53 & 0.55 & 67.14 & 69.73 \\
\hline BB & 9 & 4 & 79.78 & 4.53 & 70.03 & 91.54 \\
\hline BB & 11 & 5 & 70.59 & 7.56 & 45.71 & 85.88 \\
\hline BB & 13 & 3 & 65.92 & 5.15 & 55.81 & 72.71 \\
\hline BB & 185 & 5 & 73.06 & 4.19 & 58.15 & 82.88 \\
\hline BB & 190 & 3 & 69.60 & 2.79 & 64.02 & 72.46 \\
\hline
\end{tabular}

